\title{
Smoke control in case of fire in a large car park: CFD Simulations of Full-Scale Configurations
}

\author{
X. Deckers ${ }^{1,2}$, S. Haga $^{1,3}$, N. Tilley ${ }^{1}$ and B. Merci ${ }^{1}$ \\ ${ }^{1}$ Ghent University, Dept. Flow, Heat and Combustion Mechanics, Belgium \\ ${ }^{2}$ Fire Engineered Solutions BVBA, Belgium \\ ${ }^{3}$ NorConsult, Norway
}

\begin{abstract}
Computational Fluid Dynamics (CFD) simulation results are presented of full-scale car park fire experiments with smoke and heat control (SHC) by forced mechanical horizontal ventilation. A well-controlled liquid pool fire heat release rate (HRR) is set as an input parameter. The effect of the SHC system on the smoke movement in fire conditions is examined. The following parameters are varied: fire HRR; smoke extraction flow rate; openings for incoming air (so that different flow patterns have been created); presence of beams. The impact of jet fans (induction type) is also addressed in a number of simulations. The trends observed in the full-scale experimental campaign are well captured and additional insight is provided for the interpretation of the results. The sensitivity of the CFD results to input parameters is highlighted. For a $4 \mathrm{MW}$ HRR fire, which is the order of magnitude for a car fire, the required ventilation velocity to limit smoke back-layering in a flat ceiling car park is around $1.1 \mathrm{~m} / \mathrm{s}$. When beams are present, the average velocity must be higher, particularly for longitudinal beams. If smoke is trapped inside a recirculation region, increasing the smoke extraction rate does not help to remove the smoke.
\end{abstract}

Keywords: Car park fire safety; smoke and heat control; CFD simulations 


\section{Introduction}

In this paper, Computational Fluid Dynamics (CFD) simulation results are presented regarding smoke and heat control (SHC) by forced mechanical horizontal ventilation in case of a car park fire. the settings correspond to the full-scale experimental campaign, as described in [1]. The reader is referred to [1] for a complete description of the experimental set-up, including the accuracy of the data. The heat release rate (HRR) of the fire, introduced as well-controlled liquid pool fire, is an input parameter in the study of the effect of the SHC system on the smoke movement in fire conditions. The motivation of the study concerns the need for scientific support in the development of standards and guidelines for design of SHC systems in car parks, which cannot be treated as 'tunnel-like' geometries (see e.g. [2]). In tunnel geometries, zone modeling can be applied in regions far away from the fire (see e.g. [3]). Flow patterns in car parks can be complex and flow momentum always plays a crucial role, so that the use of zone models, where momentum equations are not solved, is not recommended.

The fire (size and heat release rate) is introduced as input parameter for the problem. The choice of design fire for use in standards for design of SHC systems in car parks constitutes an interesting study on itself. The reader is referred to [4] for a discussion on this topic, based on recent full-scale tests and statistics from car park fire hazards.

The use of CFD for calculations of smoke movement in case of fire in complex buildings is increasingly popular. This is not only reflected in a large number of recent journal publications, a few examples of which are references [3,5-9], but it is also becoming more and more common practice in design calculations. Therefore, it is very important to gain trust in CFD on one hand, and to illustrate sensitivity in CFD results to e.g. mesh size and boundary conditions on the other hand. Consequently, this paper targets multiple objectives. Firstly, it is illustrated that the trends 
observed in the results of the full-scale experimental campaign of [1] are well captured in the CFD simulations. Secondly, additional insight is provided for the interpretation of the results, thanks to additional information from CFD that has not been measured. Throughout the paper an indication is provided regarding the sensitivity of the CFD results to input parameters.

The results discussed below stem from more than 500 CFD simulations. They have been obtained with FDS, version 5.4.1 [10]. The authors are well aware of the fact that FDS has not been designed as a CFD code for research purposes and the authors are also well aware that the meshes used below are not sufficiently fine to guarantee high-quality LES (Large-Eddy Simulations) results (see e.g. $[9,11,12]$ for more discussion on this point). On the other hand, the package is used worldwide for design calculations, with meshes comparable to what is used below, so already for the sake of practical relevance, it makes sense to investigate the potential and limitations of the code in the context of reproducing full-scale experimental test results. Moreover, the issue is not to examine in all detail e.g. the flow around the fire source or the entrainment of air into smoke. Rather, the goal of the study is in the first place to explore to what extent smoke patterns can be predicted, more particularly the smoke back-layering distance for a number of set-ups. To that purpose, FDS is very well-suited, since results can be obtained within reasonable computing times. Whereas it is worth-wile to examine the performance of other CFD packages as well, such a comparative study is work in progress and considered beyond the scope of the present paper.

As mentioned, it is investigated first to what extent the trends in the experimental results of [1] are captured in the CFD simulations. The following parameters are varied:

- Fire HRR; 
- Smoke extraction flow rate;

- Opening for incoming air (so that different flow patterns have been created);

- Presence of beams.

The impact of jet fans (induction type) is also addressed in a number of simulations.

The structure of the paper is as follows. First of all, the global set-up of the CFD simulations is described. Secondly, the accuracy, in terms of sensitivity, and the manner of presentation of the results is explained. Finally, the comparison to the experimental data of [1] is provided.

\section{Set-up of the Numerical Simulations}

First, the basic simulation settings are described. Afterwards, the sensitivity study is briefly introduced. More details on the sensitivity study are found in section 4 during the discussion of the results. Figure 1 provides a schematic view of the set-up. The basic simulation settings are:

- Car park dimensions: $28.6 \mathrm{~m}$ (width) x $30 \mathrm{~m}$ (length) x $2.7 \mathrm{~m}$.

- Mesh cells size: $0.2 \mathrm{~m}$ x $0.2 \mathrm{~m}$ x $0.15 \mathrm{~m}$ (refinement near the ceiling: $0.05 \mathrm{~m}$ ).

- Models:

○ Turbulence model: standard Smagorinsky LES, $C_{D}=0.20$.

- Baroclinic generation of vorticity has been taken into account.

○ Combustion model: default mixture fraction combustion model.

- Smoke production: conversion of a fixed fraction of consumed fuel mass into smoke particulates, with 'soot yield' set to 0.22 , in agreement with e.g. [13].

○ Radiation: fixed percentage heat loss, in order to eliminate uncertainty from radiation modelling. The default value used is $20 \%$. The sensitivity to this choice is discussed below. 
- Boundary conditions:

- The ceiling, floor and side walls are adiabatic. In real car parks there can be conductive heat losses to the structure.. Admittedly, heat losses from the smoke layer through the structure can lead to more de-stratification of the smoke layer due to reduced buoyancy force. Yet, this is not crucial for the present study: the smoke back-layering distance, given the fire source and ventilation conditions, is hardly affected by the adiabatic assumption and the smoke-free height within the region of smoke back-layering is of secondary importance. As such, for smoke control calculations, the adiabatic boundary condition is reasonable [9] Moreover, the ceiling is well insulated in all experiments [1].

- The 4 equidistant supporting beams under the ceiling have depth $25 \mathrm{~cm}$ and width $20 \mathrm{~cm}$. The columns have dimensions $0.2 \mathrm{~m}$ x $0.2 \mathrm{~m}$.

- The smoke extraction rate is imposed through 4 openings in the ceiling of $1 \mathrm{~m} \mathrm{x}$ $1 \mathrm{~m}$ each, positioned $1 \mathrm{~m}$ from the back wall.

- The surrounding environment, as in reality for the large-scale experiments of the research project, is considered. The domain has been extended $15 \mathrm{~m}$ in front of the car park opening, $1.8 \mathrm{~m}$ laterally at each side, $3 \mathrm{~m}$ at the back side and $0.9 \mathrm{~m}$ vertically above the car park. Atmospheric pressure boundary conditions are imposed at all exterior boundaries (open vents). Possible wind effects are not taken into account, as wind conditions were fortunately very mild during the experiments [1].

$\circ$ The fire is modelled as a fuel source of fixed area $(3 \mathrm{~m} \times 1.5 \mathrm{~m})$ at height equal to $45 \mathrm{~cm}$, corresponding to the situation in the experiments of [1], in the middle of 
the car park. All simulations concern (quasi-)steady state conditions with fixed heat release rate. As in the experiments [1], hexane $\left(\mathrm{C}_{6} \mathrm{H}_{14}\right)$ is used as fuel.

The sensitivity study concerns:

- The mesh: results of mesh refinement are shown in the next section for one case to illustrate the results on the basic mesh can be trusted as sufficiently accurate for the sake of the present paper (namely to capture trends in different configurations accurately).

- The fire source: the height of the pool fire has been varied from $45 \mathrm{~cm}$ height to flush with the floor.

- Radiative heat loss fraction $(10 \%, 30 \%, 50 \%)$.

- The geometry:

○ Presence of beams.

- Position of the extraction fans.

- Variation of the fire HRR and smoke extraction rate by $+/-10 \%$, in order to quantify the effect of such variations on the calculated smoke back-layering distance. 


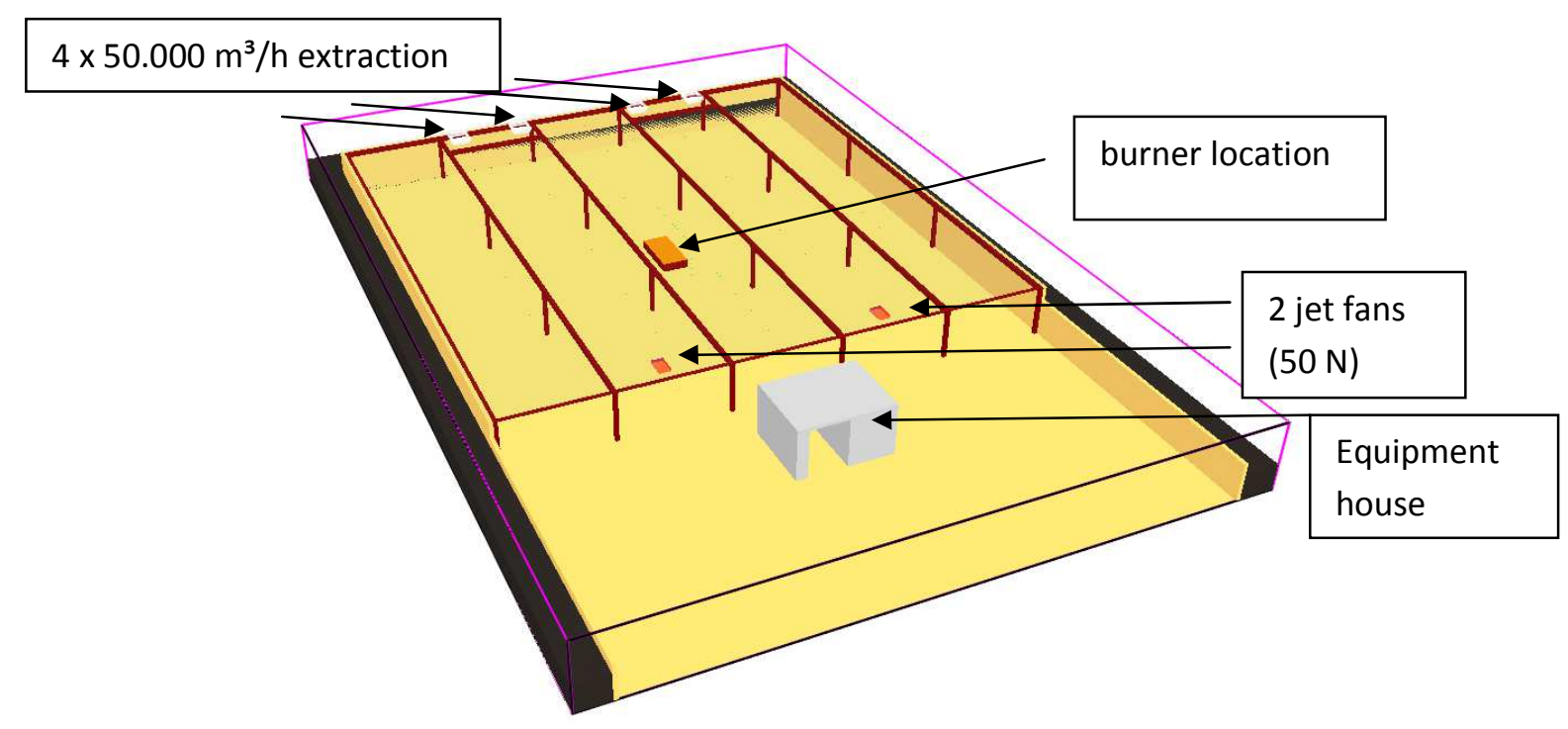

Figure 1. Schematic presentation of the car park as modelled in the simulations.

Some of the experiments in [1] included 2 induction type jet fans with $50 \mathrm{~N}$ thrust each. Special care must be taken when fans are included in CFD simulations. Therefore, the way the fans have been introduced in our simulations, is described first here. The jet fan exit flow is not horizontal: there is a downward angle, in order to avoid a Coanda effect under the ceiling. It is important to include this downward angle in the simulations. Not only the downward angle is important, also the distance from the ceiling must be respected as accurately as possible. Differences have been observed between flow fields from a jet fan, mounted at the ceiling, and the same jet fan, $10 \mathrm{~cm}$ below the ceiling (not shown). Apart from the vertically downward angle, also a horizontal angle must be given to the flow at the fan exit plane, in order to 'stimulate' the spreading rate of the jet fan stream, which is otherwise under-predicted in the numerical simulations for the meshes applied in the present paper. The fan exit plane is divided into 3 equal parts, each accounting for $1 / 3^{\text {rd }}$ of the $50 \mathrm{~N}$ thrust. The velocity imposed $(21.6 \mathrm{~m} / \mathrm{s})$ has been split into a different horizontal, vertical and transversal component in each of the 3 parts. In the central part, the flow 
is perpendicular to the fan exit plane, whereas in the side parts an outward horizontal angle is given to the flow to resemble the jet spreading rate. A sideward angle of $10^{\circ}$ seems reasonable to that purpose [14] (where, admittedly, the jet fans are of a different type and the simulations were performed with RANS turbulence models). However, in situ velocity measurements revealed that the flow out of the fans' exit plane was not at all uniform in the experiments of [1]. The main reason is most probably the fact that the fan is not positioned centrally inside the jet fan device. Based on the velocity measurements, the 3 parts of the jet fan were modeled with a downward angle of $25^{\circ}$, the left part with a horizontal outward angle of $18^{\circ}$ and the middle and right part with a flow perpendicular to the exit plane. In general, it is clear that detailed information on the flow pattern at the jet fan exit plane and the first few meters downstream is important to guarantee reliable CFD simulations with jet fans. With the information currently available on the technical specification sheets of jet fans (velocity, flow rate and thrust), the characteristics of the jet flow are not sufficiently described.

\section{Simulation Results: Presentation and Uncertainty}

Most results are presented in terms of temperature profiles along lines, with data collected at exactly the same positions of the thermocouples in [1], i.e. at different positions, $5 \mathrm{~cm}$ below the ceiling. Obviously, there is unsteadiness in the results, due to the inherent nature of LES simulations. The data as presented have been averaged over a period of $40 \mathrm{~s}$. The exact length of the averaging period is not crucial, as long as it is sufficiently longer than typical fluctuation times in the physical problem at hand (which are in the order of seconds here, e.g. the puffing frequency of the fire source). 
Additionally, contour plots of velocity and temperature are presented in horizontal or vertical planes, in order to provide additional insight. For obvious reasons, such results cannot be directly compared to experimental data.

With respect to uncertainties, a number of potential issues in the experiments are absent in numerical simulations. Indeed, when a fire HRR or a smoke extraction rate is imposed, it is in principle perfectly imposed in the simulations, while there is inevitable uncertainty in the reallife experiments. Therefore, a sensitivity study is presented as well below, so that in that sense an indication is found with respect to 'uncertainty' in the CFD results, from the point of view of comparison to experimental data.
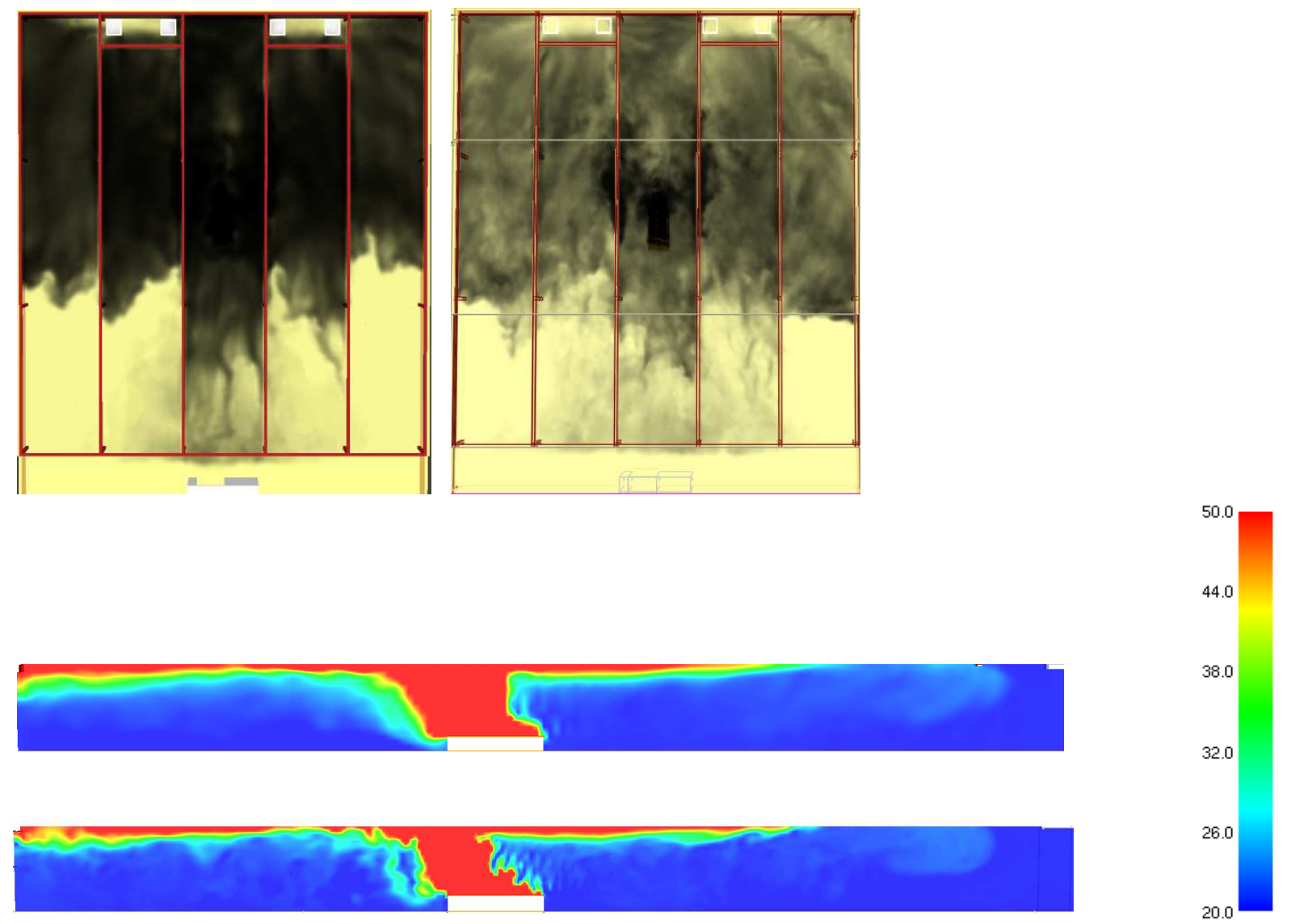


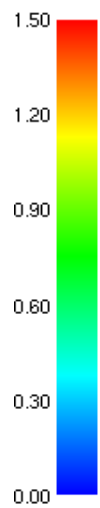

Figure 2. Comparison of results on the default mesh used in this paper (left) and a uniform mesh with cells of $0.1 \mathrm{~m} \times 0.1 \mathrm{~m} \times 0.1 \mathrm{~m}$ (right): top view of instantaneous smoke pattern after $120 \mathrm{~s}$ (top) and averaged (over $40 \mathrm{~s}$ ) temperatures (middle pictures) and velocities (bottom pictures) in vertical symmetry plane in steady state conditions. HRR $=500 \mathrm{~kW}$, extraction rate $=200000$ $\mathrm{m}^{3} / \mathrm{h}$

Obviously, CFD results depend on the mesh chosen for the calculations [11,12]. Therefore, it is important to illustrate that the mesh chosen is appropriate. This is not done for all simulations, as this would be too cumbersome and time-consuming. Results are presented here for a steady-state fire of $500 \mathrm{~kW}$ and extraction rate equal to $200000 \mathrm{~m}^{3} / \mathrm{h}$. Figure 2, however, showing instantaneous smoke patterns after $120 \mathrm{~s}$ (top view) and averaged (over $40 \mathrm{~s}$ ) temperatures and velocities in the vertical symmetry plane in steady state conditions, reveals that results obtained on the basic mesh can be trusted for the objectives in the present paper. The figures on the left hand side (top view of smoke pattern) and the upper side (averaged temperatures and velocities in the vertical symmetry plane) have been obtained on a mesh with cubic cells of size $0.2 \mathrm{~m} \times 0.2$ $\mathrm{m} \times 0.15 \mathrm{~m}$ (and refinement to $0.05 \mathrm{~m}$ near the ceiling), while the other ones stem from a uniform mesh with cells of $0.1 \mathrm{~m} \times 0.1 \mathrm{~m} \times 0.1 \mathrm{~m}$. As expected, more detail is observed on the 
finer mesh, but the global picture, definitely in terms of smoke back-layering as well as temperature fields and flow pattern, is very similar on both meshes.

In section 4.c, the influence of the flow pattern is investigated. Therefore, we also present results from a grid sensitivity study for the $500 \mathrm{~kW}$ fire (extraction rate equal to $200000 \mathrm{~m}^{3} / \mathrm{h}$ ) in a setup where $80 \%$ of the inlet opening is blocked, and a large recirculation region is created (XXXXO configuration, see Table 2). Figure 3 shows mean temperature contours (averaged over a period of $40 \mathrm{~s}$ ) in the horizontal plane at ceiling level. Generally higher temperatures are obtained on the finer mesh, but the global pattern does not change substantially. Also the flow pattern remains very similar (not shown).

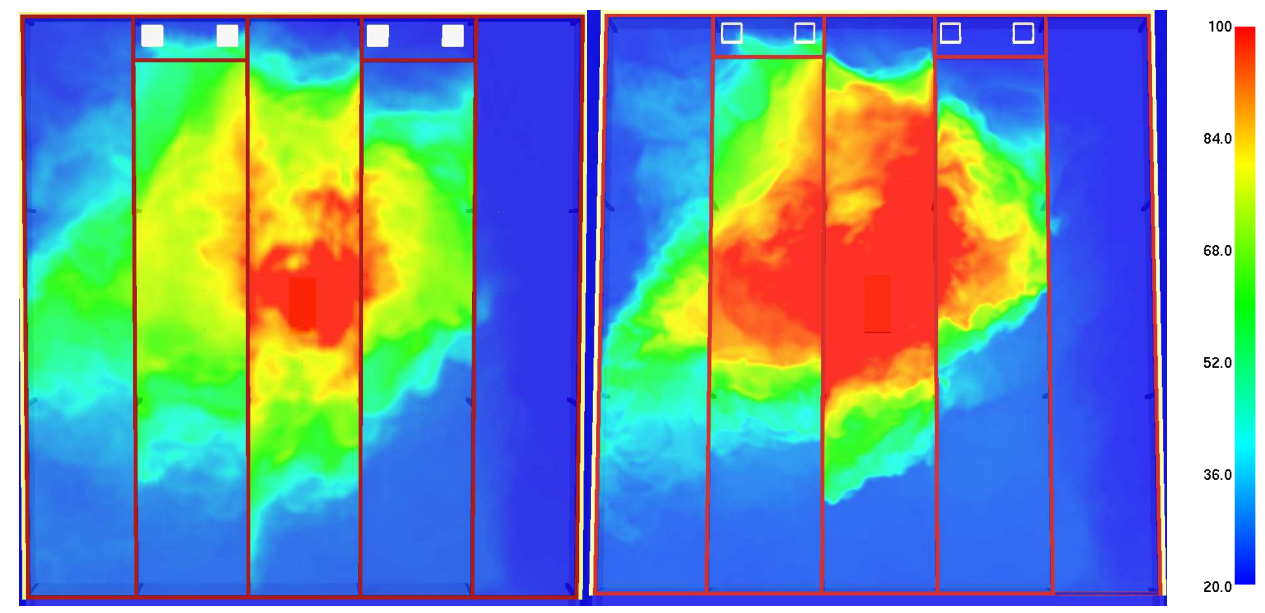

Figure 3. Comparison of results on a mesh with the default mesh used in this paper (left) and a uniform mesh with cells of $0.1 \mathrm{~m} \times 0.1 \mathrm{~m} \times 0.1 \mathrm{~m}$ (right): top view of averaged (over $40 \mathrm{~s}$ ) temperature contours at ceiling level after $120 \mathrm{~s}$. HRR $=500 \mathrm{~kW}$, extraction rate $=200000$ $\mathrm{m}^{3} / \mathrm{h}$.

As the grid study reveals no substantial changes with respect to the smoke pattern, the results below are therefore only presented on the 'basic mesh' as described in the previous section. 


\section{Simulations of Full-Scale Experiments}

It is important to appreciate that, while most of the results are presented in terms of temperature profiles, the actual end result concerns the shape of the smoke pattern, more particularly in terms of smoke back-layering distance. It is not intended to compare absolute temperatures directly. To that purpose, a radiation correction on the measurement data would be necessary. Such a correction concerns the solution of a heat transfer balance equation (see e.g. [15]). For the configuration at hand, with the thermocouples mounted a few $\mathrm{cm}$ below the ceiling, this is not a straightforward task. The thermocouples receive incoming radiation from the fire source (this fraction must be estimated), transfer heat by convection with the gas in which they are immersed (air or smoke, depending on the thermocouple location) and 'see' the ceiling and the floor and side walls for exchange of radiation. Yet, as long as the temperatures are used to determine whether smoke is present or not, the absolute values are not essential. It is the shape of the temperature profiles which determines up to what location smoke is present.

Table 1 first provides an overview of the full-scale experiments of [1]. The notation for the configurations is introduced in Table 2. The letter ' $\mathrm{O}$ ' refers to 'open', while ' $\mathrm{X}$ ' denotes 'blocked'. V1 - V4 refer to the extraction fans. The column 'Jet-fans' indicates whether the jet fans have been activated or not. The column 'Beam' refers to the presence of a transversal beam or not. 


\begin{tabular}{|c|c|c|c|c|c|c|c|c|c|c|c|}
\hline Campaign & Test number & Test letter & Configuration & HRR (kW) & Extraction (m3/h) & v4 & v3 & v2 & v1 & Jet-fans & Beam \\
\hline 1 & 1 & & 00000 & 750 & 200,000 & on & on & on & on & - & No \\
\hline 1 & 2 & & 00000 & 1250 & 200,000 & on & on & on & on & - & NO \\
\hline 1 & 3 & a & 00000 & 200 & 200,000 & on & on & on & on & - & No \\
\hline 1 & 3 & $b$ & 00000 & 200 & 100,000 & on & - & - & on & - & NO \\
\hline 1 & 3 & c & 00000 & 200 & 139,000 & on & $25 \mathrm{~Hz}$ & $25 \mathrm{~Hz}$ & on & - & No \\
\hline 1 & 3 & d & 00000 & 200 & 188,000 & on & $40 \mathrm{~Hz}$ & $40 \mathrm{~Hz}$ & on & - & No \\
\hline 1 & 3 & e & 00000 & 200 & 100,000 & - & $50 \mathrm{~Hz}$ & $50 \mathrm{~Hz}$ & - & - & No \\
\hline 1 & 4 & & 00000 & 500 & 200,000 & on & on & on & on & - & No \\
\hline 1 & 5 & & 00000 & 500 & 100,000 & on & - & - & on & - & $\mathrm{NO}$ \\
\hline 1 & 6 & & 00000 & 500 & 100,000 & on & - & - & on & Active & NO \\
\hline 1 & 7 & & 00000 & 500 & 200,000 & on & on & on & on & Active & No \\
\hline 1 & 8 & & 00000 & 4000 & 200,000 & on & on & on & on & Active & NO \\
\hline 1 & 9 & & 00000 & 4000 & 200,000 & on & on & on & on & - & No \\
\hline 1 & 10 & & $\times 0000$ & JVB test & 200,000 & on & on & on & on & - & $\mathrm{NO}$ \\
\hline 1 & 11 & & 200000 & 500 & 200,000 & on & on & on & on & - & $\mathrm{NO}$ \\
\hline 1 & 12 & & 200000 & 1000 & 200,000 & on & on & on & on & - & No \\
\hline 1 & 13 & & 200000 & 2000 & 200,000 & on & on & on & on & - & $\mathrm{NO}$ \\
\hline 1 & 14 & & 200000 & 4000 & 200,000 & on & on & on & on & - & $\mathrm{NO}$ \\
\hline 1 & 15 & & 200000 & 4000 & 200,000 & on & on & on & on & Active & No \\
\hline 1 & 16 & & 200000 & 500 & 200,000 & on & on & on & on & Active & $\mathrm{NO}$ \\
\hline 1 & 17 & a & 200000 & 200 & 200,000 & on & on & on & on & - & No \\
\hline 1 & 17 & $b$ & 200000 & 200 & 100,000 & on & - & - & on & - & No \\
\hline 1 & 17 & C & 200000 & 200 & 100,000 & on & on & - & - & - & NO \\
\hline 1 & 18 & & $0 \times 00 \times 0$ & 500 & 200,000 & on & on & on & on & - & $\mathrm{NO}$ \\
\hline 1 & 19 & & $0 \times 00 \times 0$ & 500 & 200,000 & on & on & on & on & Active & $\mathrm{NO}$ \\
\hline 1 & 20 & & $0 \times 00<0$ & 4000 & 200,000 & on & on & on & on & Active & $\mathrm{NO}$ \\
\hline 2 & 1 & a & $30 \times 0 \times 0$ & 200 & 200,000 & on & on & on & on & - & $\mathrm{NO}$ \\
\hline 2 & 1 & $b$ & $20<0 \times 0 x$ & 200 & 100,000 & on & - & - & on & - & $\mathrm{NO}$ \\
\hline 2 & 1 & c & $x<0 \times 0$ & 200 & 100,000 & - & on & on & - & - & $\mathrm{NO}$ \\
\hline 2 & 2 & a & $20<0 \times 0 \times$ & 500 & 200,000 & on & on & on & on & - & $\mathrm{NO}$ \\
\hline 2 & 2 & $b$ & $x<0 \times x$ & 500 & 100,000 & on & - & - & on & - & No \\
\hline 2 & 2 & c & $20 \times 0 \times 10 x$ & 500 & 100,000 & - & on & on & - & - & No \\
\hline 2 & 2 & d & $20 \times 0 \times x$ & 500 & 39,000 & - & $25 \mathrm{~Hz}$ & $25 \mathrm{~Hz}$ & - & - & NO \\
\hline 2 & 3 & a & $20 \times 0 \times 2 x$ & 500 & 200,000 & on & \begin{tabular}{|l|} 
on \\
\end{tabular} & on & on & Active & $\mathrm{NO}$ \\
\hline 2 & 3 & $b$ & $30 \times 0 \times 0$ & 500 & 100,000 & on & - & - & on & Active & NO \\
\hline 2 & 3 & C & $20 \times 0 \times 0 x$ & 500 & 100,000 & - & on & on & - & Active & No \\
\hline 2 & 4 & a & $20 \times 0 \times 0$ & 1000 & 150,000 & - & on & on & on & Active & NO \\
\hline 2 & 4 & $b$ & $20<0 \times 10 x$ & 1000 & 150,000 & - & on & on & on & - & No \\
\hline 2 & 5 & a & $x<0 \times x$ & 2000 & 150,000 & - & on & on & on & - & NO \\
\hline 2 & 5 & abis & $20<0 \times 10 x$ & 2000 & 200,000 & on & on & on & on & - & NO \\
\hline 2 & 5 & $b$ & $x<0 \times 0 x$ & 2000 & 200,000 & on & on & on & on & Active & NO \\
\hline 2 & 6 & a & $20<0 \times 0 x$ & 4000 & 200,000 & on & on & on & on & Active & $\mathrm{NO}$ \\
\hline 2 & 6 & $b$ & $20 \times 0 \times 0$ & 4000 & 200,000 & on & on & on & on & - & No \\
\hline 2 & 7 & a & $20 \times 0 \times 0 x$ & 200 & 200,000 & on & on & on & on & - & YES \\
\hline 2 & 7 & $b$ & $20 \times 0 \times 0$ & 200 & 100,000 & on & - & - & on & - & YES \\
\hline 2 & 7 & c & $20 \times 0 \times 0$ & 200 & 100,000 & - & on & on & - & - & YES \\
\hline 2 & 8 & $a$ & $20 \times 0 \times 2 x$ & 500 & 200,000 & on & on & on & on & - & YES \\
\hline 2 & 8 & $b$ & $20 \times 0 \times 0 x$ & 500 & 100,000 & on & - & - & on & - & $\mathrm{YES}$ \\
\hline 2 & 8 & c & $20 \times 0 \times 0$ & 500 & 100,000 & - & on & on & - & - & YES \\
\hline
\end{tabular}

Table 1. Overview of all tests in [1]. 


\begin{tabular}{|c|c|c|c|c|c|c|c|c|c|c|c|}
\hline 2 & 8 & d & $20 \times 0 \times x$ & 500 & 39,000 & - & $25 \mathrm{~Hz}$ & $25 \mathrm{~Hz}$ & - & - & VES \\
\hline 2 & 9 & $\mathrm{a}$ & $20 \times 0 \times 0 x$ & 500 & 200,000 & on & on & on & on & Active & YES \\
\hline 2 & 9 & $\mathrm{~b}$ & $20 \times 0 \times 0$ & 500 & 100,000 & on & - & - & on & Active & $\mathrm{YES}$ \\
\hline 2 & 9 & c & $20 x 0 \times 0 x$ & 500 & 100,000 & - & on & on & - & Active & $\mathrm{YES}$ \\
\hline 2 & 10 & a & $20 \times 0 \times x$ & 1000 & 100,000 & - & on & on & - & Active & $\mathrm{YES}$ \\
\hline 2 & 10 & abis & $x 000 \times$ & 1000 & 200,000 & on & on & on & on & Active & YES \\
\hline 2 & 10 & $\mathrm{~b}$ & $20 \times 0 \times 0$ & 1000 & 200,000 & on & on & on & on & - & YES \\
\hline 2 & 11 & a & $20 \times 0 \times 0 x$ & 2000 & 200,000 & on & on & on & on & - & $\mathrm{YES}$ \\
\hline 2 & 11 & $\mathrm{~b}$ & $20 \times 0 \times x$ & 2000 & 200,000 & on & on & on & on & Active & $\mathrm{YES}$ \\
\hline 2 & 12 & a & $20 \times 0 \times 0$ & 4000 & 200,000 & on & on & on & on & Active & YES \\
\hline 2 & 12 & b & $20 \times 0 \times 0$ & 4000 & 200,000 & on & on & on & on & - & $\mathrm{YES}$ \\
\hline 2 & 13 & & $0 \times 00 \times 0$ & 500 & 200,000 & on & on & on & on & - & $\mathrm{YES}$ \\
\hline 2 & 14 & & $0 \times 0 \times 0$ & 500 & 200,000 & on & on & on & on & Active & $\mathrm{YES}$ \\
\hline 2 & 15 & & $0 \times 00 \times 0$ & 4000 & 200,000 & on & on & on & on & Active & YES \\
\hline 2 & 16 & a & 00000 & 200 & 200,000 & on & on & on & on & - & $\mathrm{YES}$ \\
\hline 2 & 16 & b & 00000 & 200 & 100,000 & on & - & - & on & - & YES \\
\hline 2 & 16 & c & 00000 & 200 & 100,000 & - & on & on & - & - & $\mathrm{YES}$ \\
\hline 2 & 17 & $\mathrm{a}$ & 00000 & 500 & 200,000 & on & on & on & on & - & YES \\
\hline 2 & 17 & $b$ & 00000 & 500 & 100,000 & on & - & - & on & - & $\mathrm{YES}$ \\
\hline 2 & 17 & c & 00000 & 500 & 100,000 & - & on & on & - & - & $\mathrm{YES}$ \\
\hline 2 & 18 & & 00000 & 500 & 200,000 & on & on & on & on & Active & $\mathrm{YES}$ \\
\hline 2 & 19 & & 00000 & 500 & 200,000 & on & on & on & on & - & YES \\
\hline 2 & 20 & & 00000 & 1500 & 200,000 & on & on & on & on & - & $\mathrm{YES}$ \\
\hline 2 & 21 & & 00000 & 2000 & 200,000 & on & on & on & on & - & $\mathrm{YES}$ \\
\hline 2 & 22 & & 00000 & 3000 & 200,000 & on & on & on & on & - & $\mathrm{VES}$ \\
\hline 2 & 23 & a & 00000 & 4000 & 200,000 & on & on & on & on & - & YES \\
\hline 2 & 23 & b & 00000 & 4000 & 200,000 & on & on & on & on & Active & YES \\
\hline 2 & 24 & a & 00000 & 500 & 200,000 & on & on & on & on & - & NO \\
\hline 2 & 24 & $\mathrm{~b}$ & 00000 & 500 & 200,000 & on & on & on & on & Active & No \\
\hline 2 & 25 & & 00000 & 2000 & 200,000 & on & on & on & on & Active & NO \\
\hline 2 & 26 & & 00000 & 3000 & 200,000 & on & on & on & on & Active & NO \\
\hline 2 & 27 & & 00000 & 4000 & 200,000 & on & on & on & on & \begin{tabular}{|l|} 
Active \\
\end{tabular} & No \\
\hline 2 & 28 & & 00000 & 500 & 200,000 & on & on & on & on & Active, closer & No \\
\hline 2 & 29 & & 00000 & 2000 & 200,000 & on & on & on & on & Active, closer & No \\
\hline 2 & 30 & & 00000 & 3000 & 200,000 & on & on & on & on & Active, closer & NO \\
\hline 2 & 31 & & 00000 & 4000 & 200,000 & on & on & on & on & Active, closer & No \\
\hline 2 & VKI 1 & & $20 \times 0 \times 2 x$ & 200 & 39,000 & - & $25 \mathrm{~Hz}$ & $25 \mathrm{~Hz}$ & - & - & No \\
\hline 2 & VKI 2 & & $20 \times 0 \times 0$ & 200 & 88,000 & - & $40 \mathrm{~Hz}$ & $40 \mathrm{~Hz}$ & - & - & NO \\
\hline 2 & $\mathrm{VKI} 3$ & & $20<0 \times 2$ & 200 & 100,000 & - & $50 \mathrm{~Hz}$ & $50 \mathrm{~Hz}$ & - & - & No \\
\hline 2 & VKI 4 & & $20 \times 0 \times 0 x$ & 200 & 100,000 & $50 \mathrm{~Hz}$ & \begin{tabular}{|l}
- \\
\end{tabular} & - & $50 \mathrm{~Hz}$ & - & No \\
\hline 2 & VKI 5 & & $20 \times 0 \times 10$ & 200 & 139,000 & $50 \mathrm{~Hz}$ & $25 \mathrm{~Hz}$ & $25 \mathrm{~Hz}$ & $50 \mathrm{~Hz}$ & - & NO \\
\hline 2 & VKI 6 & & $20 \times 0 \times 0 x$ & 200 & 188,000 & $50 \mathrm{~Hz}$ & $40 \mathrm{~Hz}$ & $40 \mathrm{~Hz}$ & $50 \mathrm{~Hz}$ & - & NO \\
\hline 2 & VKI 7 & & $20 \times 0 \times 0$ & 200 & 200,000 & $50 \mathrm{~Hz}$ & $50 \mathrm{~Hz}$ & $50 \mathrm{~Hz}$ & $50 \mathrm{~Hz}$ & - & NO \\
\hline 2 & VKI 8 & & $30<0 \times 0 x$ & 500 & 200,000 & $50 \mathrm{~Hz}$ & $50 \mathrm{~Hz}$ & $50 \mathrm{~Hz}$ & $50 \mathrm{~Hz}$ & - & NO \\
\hline 2 & VKI 9 & & $20 x 0 \times 0 x$ & 500 & 188,000 & $50 \mathrm{~Hz}$ & $40 \mathrm{~Hz}$ & $40 \mathrm{~Hz}$ & $50 \mathrm{~Hz}$ & - & No \\
\hline 2 & VKI 10 & & $20 \times 0 \times 0$ & 500 & 139,000 & $50 \mathrm{~Hz}$ & $25 \mathrm{~Hz}$ & $25 \mathrm{~Hz}$ & $50 \mathrm{~Hz}$ & - & NO \\
\hline 2 & VKI 11 & & $2010 \times 2$ & 500 & 100,000 & $50 \mathrm{~Hz}$ & - & - & $50 \mathrm{~Hz}$ & - & No \\
\hline 2 & VKI 12 & & $20 \times 0 \times 0 x$ & 500 & 100,000 & - & $50 \mathrm{~Hz}$ & $50 \mathrm{~Hz}$ & - & - & NO \\
\hline 2 & VKI 13 & & $20 \times 0 \times 2 x$ & 500 & 88,000 & - & $40 \mathrm{~Hz}$ & $40 \mathrm{~Hz}$ & - & - & No \\
\hline 2 & VKI 14 & & $20 \times 0 \times 0 x$ & 500 & 39,000 & - & $25 \mathrm{~Hz}$ & $25 \mathrm{~Hz}$ & - & - & NO \\
\hline 2 & VKI 15 & & $20 \times 0 \times 0$ & 1000 & 39,000 & - & $25 \mathrm{~Hz}$ & $25 \mathrm{~Hz}$ & - & - & NO \\
\hline 2 & VKI 16 & & $20 \times 0 \times 0 x$ & 1000 & 88,000 & - & $40 \mathrm{~Hz}$ & $40 \mathrm{~Hz}$ & - & - & No \\
\hline 2 & VKI 17 & & $20 \times 0 \times 0 x$ & 1000 & 100,000 & \begin{tabular}{|l}
- \\
\end{tabular} & $50 \mathrm{~Hz}$ & $50 \mathrm{~Hz}$ & - & - & No \\
\hline 2 & VKI 18 & & $x<0 \times x$ & 1000 & 100,000 & $50 \mathrm{~Hz}$ & - & - & $50 \mathrm{~Hz}$ & - & No \\
\hline 2 & VKI 19 & & $20<0 \times 2$ & 1000 & 139,000 & $50 \mathrm{~Hz}$ & $25 \mathrm{~Hz}$ & $25 \mathrm{~Hz}$ & $50 \mathrm{~Hz}$ & - & No \\
\hline 2 & VKI 20 & & $20 \times 0 \times 0 x$ & 1000 & 188,000 & $50 \mathrm{~Hz}$ & $40 \mathrm{~Hz}$ & $40 \mathrm{~Hz}$ & $50 \mathrm{~Hz}$ & - & NO \\
\hline 2 & VKI 21 & & $20<0 \times 2$ & 1000 & 200,000 & $50 \mathrm{~Hz}$ & $50 \mathrm{~Hz}$ & $50 \mathrm{~Hz}$ & $50 \mathrm{~Hz}$ & - & No \\
\hline
\end{tabular}

Table 1 (Continued). Overview of all tests in [1]. 


\begin{tabular}{|l|l|}
\hline Notation & Description \\
\hline XXXXO & Inlet opening $80 \%$ blocked; only the rightmost part is open. \\
\hline OXXXO & Inlet opening $60 \%$ blocked and the closure is in the middle. \\
\hline XXOXX & Inlet opening $80 \%$ blocked and the opening is in the middle. \\
\hline OOOOO & Inlet opening is fully open. \\
\hline
\end{tabular}

Table 2. Notation for inlet opening configuration.

\section{a. Impact of Fire Heat Release Rate}

Figure 4 reveals that the trends with increasing fire HRR (but keeping the fire size fixed) are well captured in FDS in the OOOOO configuration. The radiation heat loss percentage has been set to $20 \%$ in the simulations. The maximum temperatures are under-predicted, but the global profile shapes (and thus the smoke back-layering distances) are well predicted. Note that this is not surprising, as the flow is very simple: it is essentially unidirectional.

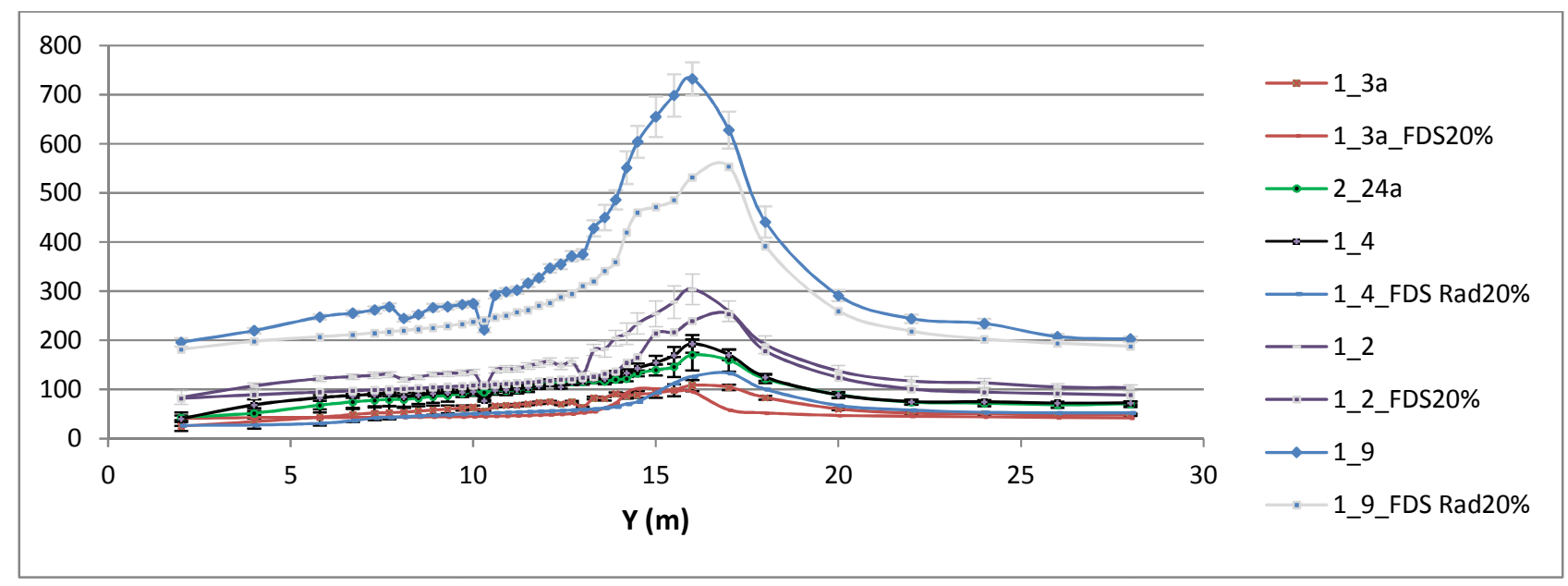

Figure 4. Mean temperature $\left({ }^{\circ} \mathrm{C}\right)$ along the centerline under the ceiling ( $\mathrm{Y}=0 \mathrm{~m}$ corresponds to the inlet opening) with variable HRR (200 kW, $500 \mathrm{~kW}, 1.25 \mathrm{MW}$ and $4 \mathrm{MW})$, no jet fans. Line names refer to Table 1. Configuration OOOOO, extraction flow rate $=200000 \mathrm{~m}^{3} / \mathrm{h}$. 
Figure 5 shows the very moderate impact of activation of the jet fans for the fire HRR of $500 \mathrm{~kW}$ and extraction rate equal to $200000 \mathrm{~m}^{3} / \mathrm{h}$. Similar findings have been obtained for other HRR values in the configuration at hand. High local velocities are found near the fans, but the effect on the temperature field, or the smoke pattern, is very small.
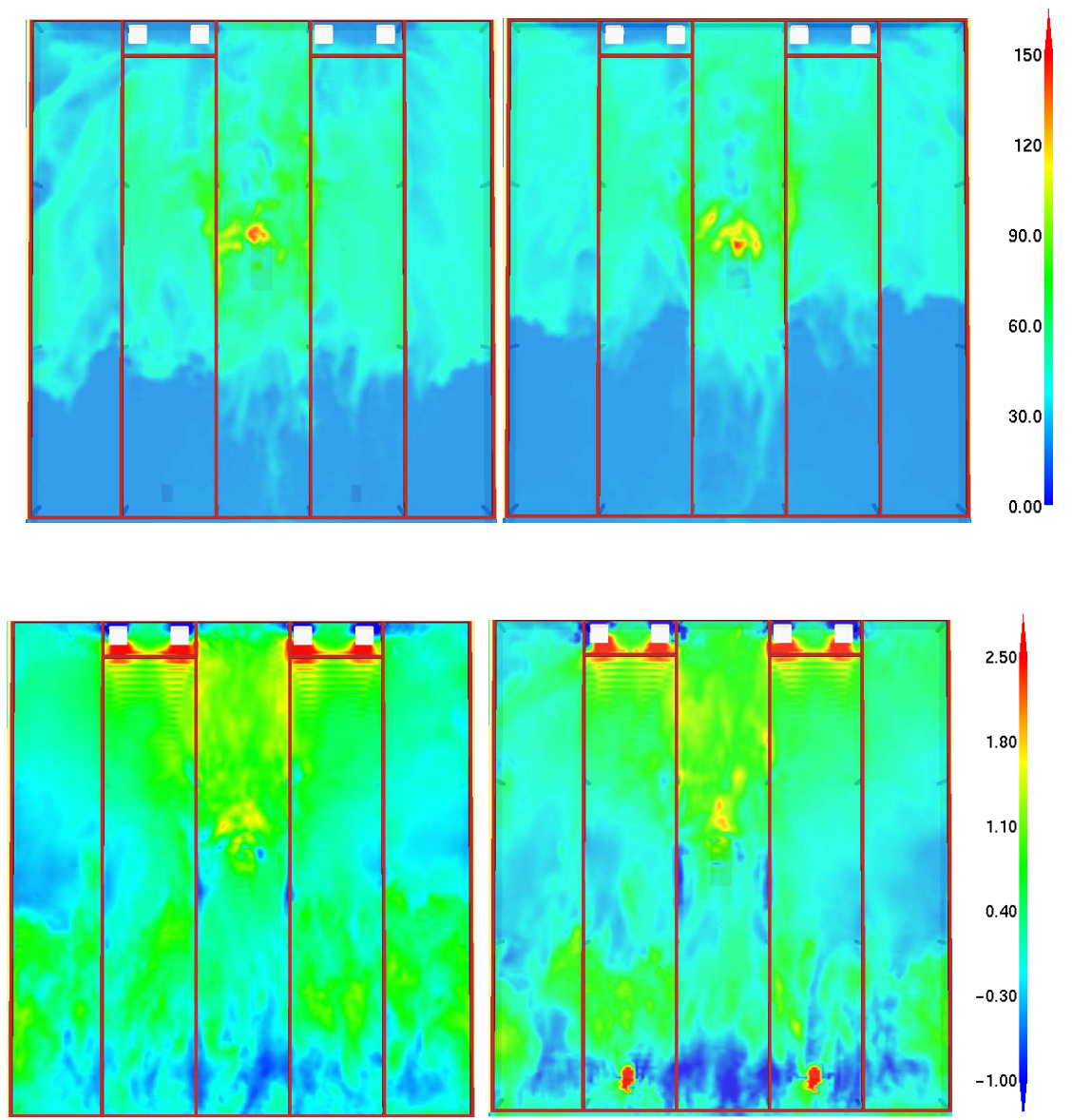

Figure 5. Temperature pattern (top) and longitudinal velocity contour plots in horizontal plane Z $=2.4 \mathrm{~m}$ without (left) and with (right) jet fans. Fire HRR $=500 \mathrm{~kW}$, smoke extraction rate $=$ $200000 \mathrm{~m}^{3} / \mathrm{h}$, jet fans each have $50 \mathrm{~N}$ thrust.

As mentioned in the introduction, a sensitivity study has been performed in the numerical simulations. Increasing the fire HRR with fixed extraction rate does not substantially modify the 
profile shapes. Only the absolute values of temperature increase (not shown), not the smoke pattern. Likewise, a modification of the radiative fraction only modifies the absolute temperature values, not so much the profile shapes. Obviously, the back-layering distance is higher for lower radiative fraction values, due to the stronger upward momentum at the fire source and the resulting stronger smoke dynamics, but the effect is not extremely strong: in Figure 6 the differences between very low (10\%) and high (50\%) values are moderate.
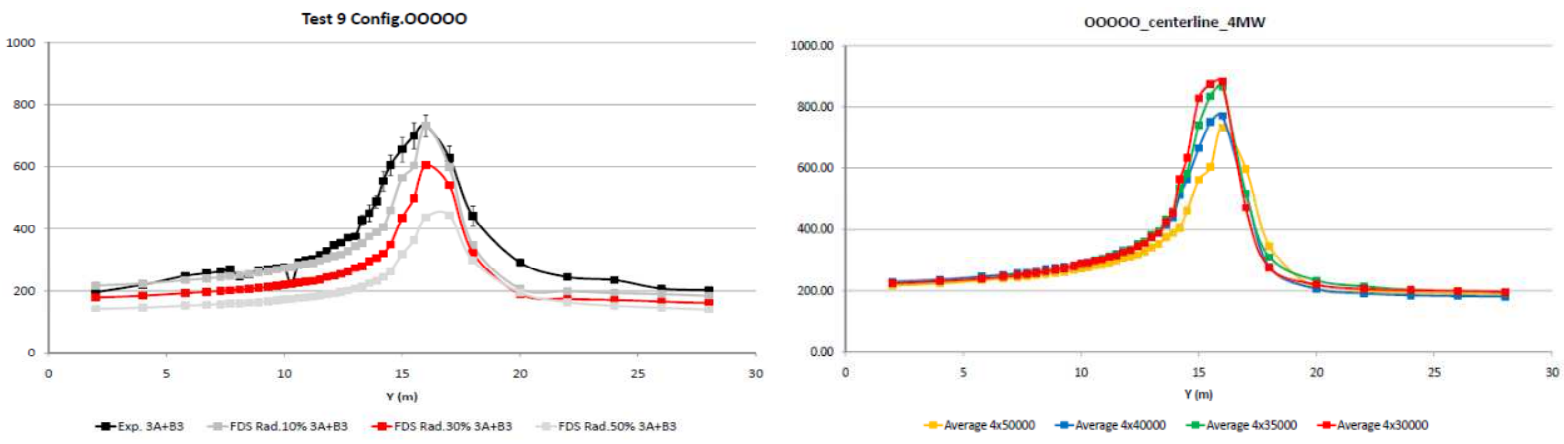

Figure 6. Mean temperature $\left({ }^{\circ} \mathrm{C}\right)$ profiles along the centerline under the ceiling from the CFD simulations: sensitivity to variations in radiative fraction (top) and smoke extraction rate (bottom). Basic smoke extraction rate $=200000 \mathrm{~m}^{3} / \mathrm{h}$.

Decreasing the extraction rate with constant fire HRR results in an upstream shift of the position of maximum temperature, as well as a temperature increase due to reduced cooling by the incoming fresh air (Figure 6). The effect of the extraction rate is stronger than the effect of the fire HRR, as is also reflected in the correlation of [16] and as has been observed in [1].

\section{b. Impact of Smoke Extraction Rate}

In this section the discussion is restricted to configurations OOOOO and XXOXX, where the oncoming air reaches the fire source in a relatively straight longitudinal manner. The discussion 
of the more complex flow patterns, and the influence thereof on the efficiency of increased smoke extraction rates, is postponed until the next section.

From Figure 6 it can already be expected that the smoke extraction rate has a strong impact on the smoke pattern and smoke back-layering distance in particular. Figure 7 presents mean temperature profiles along the centerline for OOOOO and XXOXX for HRR $=500 \mathrm{~kW}$ (left) and 4 MW (right), for different values of extraction rates. Experimental data has been added for comparison purposes.

The top left figure shows that in the OOOOO configuration, the position of the peak temperature is very well predicted for the $500 \mathrm{~kW}$ HRR with extraction flow rates $100000 \mathrm{~m}^{3} / \mathrm{h}$ and 200000 $\mathrm{m}^{3} / \mathrm{h}$. Thus, the fire plume tilting is well captured. The CFD simulations confirm the experimental observation that an extraction rate of $200000 \mathrm{~m}^{3} / \mathrm{h}$ is necessary to prevent smoke back-layering up to the car park inlet (temperature drop to ambient temperature at $\mathrm{Y}=0 \mathrm{~m}$ ). The bottom left figure confirms the good agreement between CFD and experiments for the $4 \mathrm{MW}$ HRR value. The temperature under-prediction by FDS is expected as FDS automatically applies a radiation correction to the temperature of the thermocouples. As explained, this is not essential for the present paper, though.

For XXOXX, there is practically no temperature rise for $500 \mathrm{~kW}$ for the extraction rate of $200000 \mathrm{~m}^{3} / \mathrm{h}$. This is well predicted. The shift upward( i.e. more upstream and towards higher values) for lower extraction rate is well captured. Compared to the experimental data, the simulation results are shifted towards the back wall, though (best seen for the extraction rate of $100000 \mathrm{~m}^{3} / \mathrm{h}$ ). The same observation, combined with an under-prediction of temperatures, holds for the $4 \mathrm{MW}$ case. In the next section, a more extensive discussion is devoted to the impact of 
the inlet opening configuration (e.g. Figures 9 and 10). It is already stated here that this shift back-ward in the simulations is an indication that the spreading of the incoming air flow through $\mathrm{O}$ is under-estimated in FDS, probably due to a lack of turbulence generation in the inlet opening. Despite the deviations between experiments and simulations, the trend compared to the simple OOOOO configuration is well captured. In particular noteworthy is the similarity of the profiles for $500 \mathrm{~kW}$ for 00000 with $200000 \mathrm{~m}^{3} / \mathrm{h}$ extraction rate and XXOXX with 40000 $\mathrm{m}^{3} / \mathrm{h}$ (implying the same inlet air velocity): this experimentally observed similarity is confirmed in the CFD simulations. This is re-assuring for the use as CFD complementary to experiments.
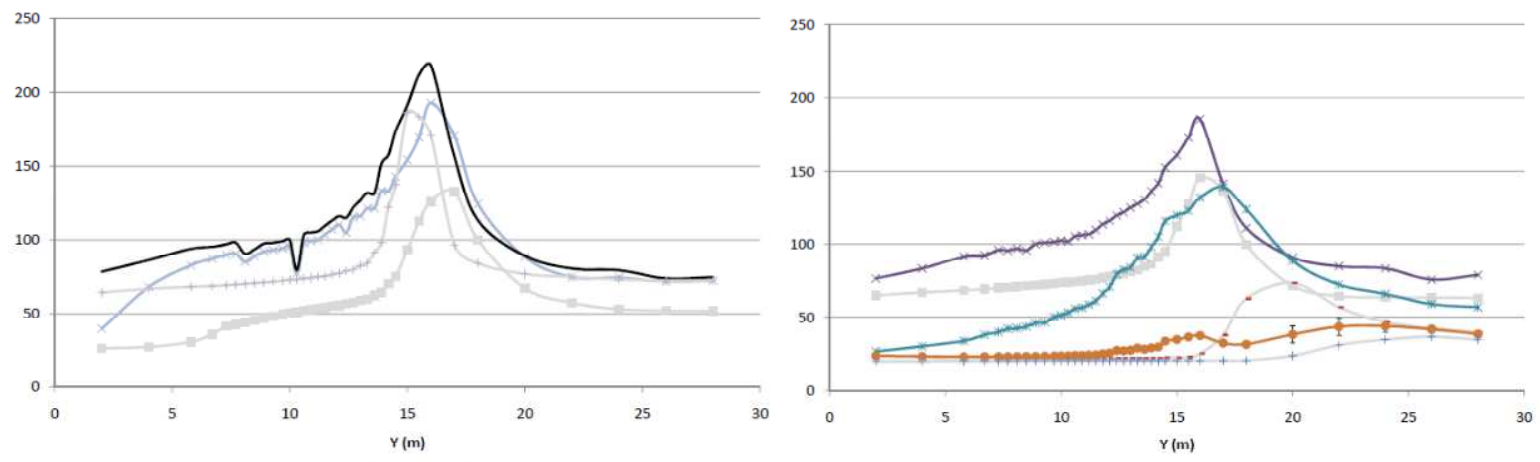

$-1 \_4-F D S 20 \% 1 \_4-1 \_5-F D S 20 \% 1 \_5$
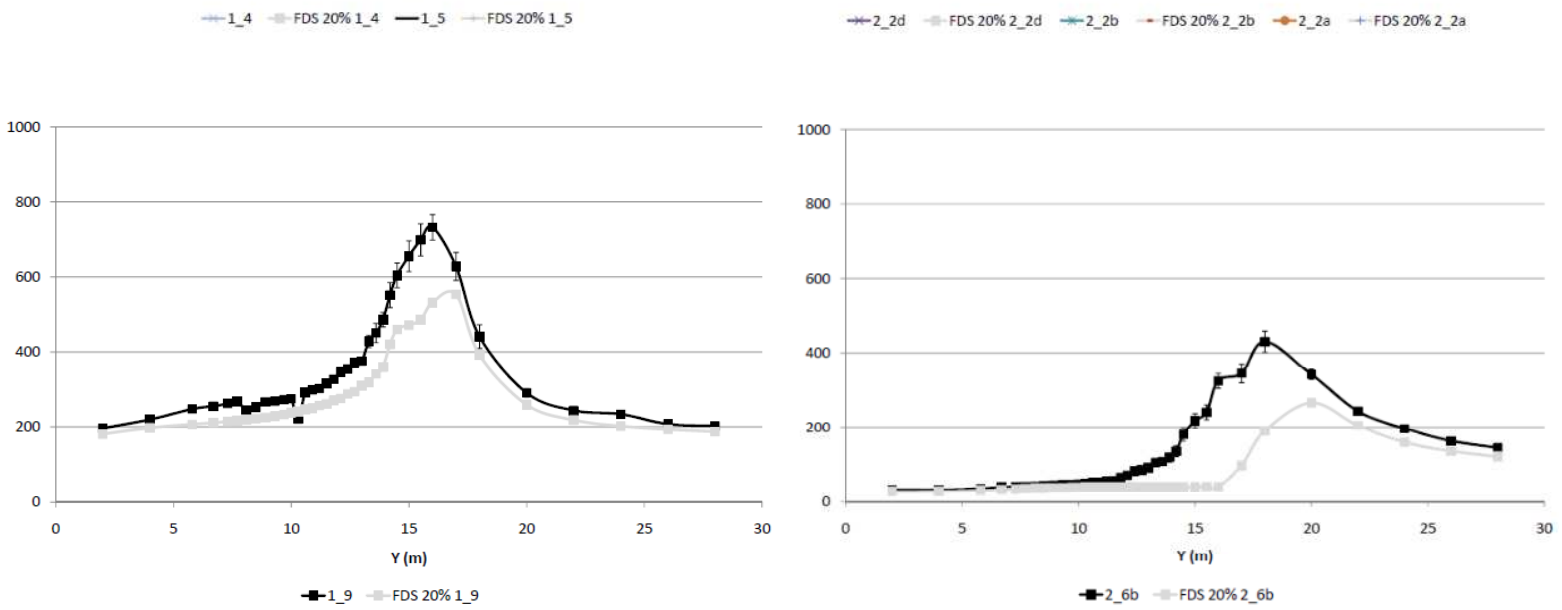
Figure 7. Mean temperature $\left({ }^{\circ} \mathrm{C}\right)$ profiles along the centerline under the ceiling. Top left: OOOOO, $500 \mathrm{~kW}$; top right: XXOXX, $500 \mathrm{~kW}$. Bottom left: OOOOO, 4 MW. Bottom right: XXOXX, 4 MW. Smoke extraction rate $=40000-200000 \mathrm{~m}^{3} / \mathrm{h}($ for $500 \mathrm{~kW})$ and $200000 \mathrm{~m}^{3} / \mathrm{h}$ (for $4 \mathrm{MW}$ ).

\section{c. Impact of Flow Pattern}

In this section, different flow patterns are discussed in more detail, along with the effect on the resulting smoke pattern for identical fire HRR and smoke extraction rate. It is a particular strength of CFD that such flow features can easily be demonstrated.

Figure 8 shows fields of longitudinal velocity in horizontal planes at height $Z=1.2 \mathrm{~m}$ (well below the smoke layer) and $\mathrm{Z}=2.65 \mathrm{~m}$ (inside the smoke layer under the ceiling), for smoke extraction rate equal to $200000 \mathrm{~m}^{3} / \mathrm{h}$ and fire HRR equal to $500 \mathrm{~kW}$, for configurations OOOOO, XXOXX, OXXXO and XXXXO. Negative values indicate recirculation. For OOOOO extremely simple, unidirectional flow patterns are observed. At $\mathrm{Z}=1.2 \mathrm{~m}$, a relatively uniform flow is seen, from inlet towards extraction. At $\mathrm{Z}=2.65 \mathrm{~m}$, behind the fire source there is stronger flow towards the extraction fans than at $\mathrm{Z}=1.2 \mathrm{~m}$, but back-flow is also observed, mainly in the central part between the fire source and the inlet opening, due to the channeling effect of the longitudinal beams. This is in line with the results discussed in section 4.a: the smoke backlayering distance exceeds $15 \mathrm{~m}$ for 00000 with $500 \mathrm{~kW}$ and extraction rate $200000 \mathrm{~m}^{3} / \mathrm{h}$ (Figure 4). Close to the fire, the highest velocities are observed due to the plume impingement onto the ceiling. For $\mathrm{XXOXX}$, at $\mathrm{Z}=1.2 \mathrm{~m}$ a strong central flow through $\mathrm{O}$ is observed, with relatively little spreading. Two recirculation regions are recognized along the side walls over the entire car park length, i.e. all the way from the back to the front. At $Z=2.65 \mathrm{~m}$, essentially the same pattern is observed. Unlike in OOOOO, the fire is now not strong enough to affect the flow 
pattern substantially. It is overwhelmed by the strong air flow. The small recirculation region close to the inlet is due to inclusion of the surroundings in the CFD simulations: a small recirculation region appears just beneath the ceiling as the air enters into the car park. In $\mathrm{OXXXO}$, at $\mathrm{Z}=1.2 \mathrm{~m}$ two strong air streams through the O's are observed and a large central recirculation region appears in the middle of these streams. This recirculation region extends from the back side, all the way to the front side. Interestingly, the fire source is thus approached by air from the back side! At $\mathrm{Z}=2.65 \mathrm{~m}$, the flow pattern is entirely different. The streams from $\mathrm{O}$ are much weaker, basically because the smoke flow from the fire source acts as an obstruction for the air flow, pushing it downward (so it is less visible than at $\mathrm{Z}=1.2 \mathrm{~m}$ height). The large central recirculation region, observed at $\mathrm{Z}=1.2 \mathrm{~m}$, is broken into 2 recirculation regions by the fire plume: one from the back side to the fire and one from the fire to the front side. The smoke that gets trapped into the latter, cannot easily be extracted. For XXXXO, at $\mathrm{Z}=1.2 \mathrm{~m}$ one strong air stream is observed from the $\mathrm{O}$ to the back. A single large counter-clockwise recirculation pattern is recognized, covering almost the entire car park. At $\mathrm{Z}=2.65 \mathrm{~m}$, the strong air stream is still clearly visible. It is pushed toward the side wall by the smoke from the fire source and close to the fire, high velocities are observed due to the plume impingement onto the ceiling. Globally the pattern does not deviate too strongly from what is observed at $\mathrm{Z}=1.2 \mathrm{~m}$.

Figure 9 provides the same information for HRR equal to $4 \mathrm{MW}$. At $\mathrm{Z}=1.2 \mathrm{~m}$, the patterns are very much alike the ones in Figure 8 . The fire is much stronger here, but the dominant effect is near the ceiling, not at low heights. Only in the XXXXO configuration, where the fire is close to the centre of the large recirculation zone, the fire is visible at $\mathrm{Z}=1.2 \mathrm{~m}$, much more than was the case in Figure 9. In general, though, it is clear that the flow pattern at low heights is determined by the geometry and the extraction rate basically. As expected, larger differences are observed at 
$\mathrm{Z}=2.65 \mathrm{~m}$. For OOOOO, the flow pattern remains conceptually the same, but with much stronger back-flow over the entire width between the fire source and the inlet opening, due to the stronger fire source. The buoyant source is much stronger so the channeling effect of the beams is not seen here. Along the side wall, back-flow is even observed all the way from the back corners of the car park up to the opening. The extraction rate is not high enough to prevent this. For XXOXX, the pattern is very similar to the one in Figure 8. The oncoming air flow is now strong enough to overcome the smoke dynamics from the $4 \mathrm{MW}$ fire. The resistance to the air flow is stronger, as visible in the breaking of the central air stream and the shift of the recirculation regions at the sides towards the front side of the car park, but the global flow pattern remains the same. This is not the case for OXXXO. The recirculation region between the back side of the car park and the fire plume is now destroyed by the dynamics of the smoke, emerging from the strong fire source. The recirculation region between the fire source and the front side now also becomes stronger and wider. The strong incoming air streams, clearly visible at $\mathrm{Z}=1.2 \mathrm{~m}$, are not observed at all at $\mathrm{Z}=2.65 \mathrm{~m}$. For $\mathrm{XXXXO}$, the difference between the 500 $\mathrm{kW}$ and the $4 \mathrm{MW}$ fire is also substantial: whereas the strong air stream is clearly visible in Figure 8 at $Z=2.65 \mathrm{~m}$, it is completely squeezed to the side wall by the strong smoke from the 4 MW fire source. Inside the large recirculation region, the plume impingement is very clear: high velocities behind the fire source towards the extraction and strong back-flow as well towards the front wall. The back-flow at the left wall is also 'broken' by the smoke impingement flow under the ceiling. 

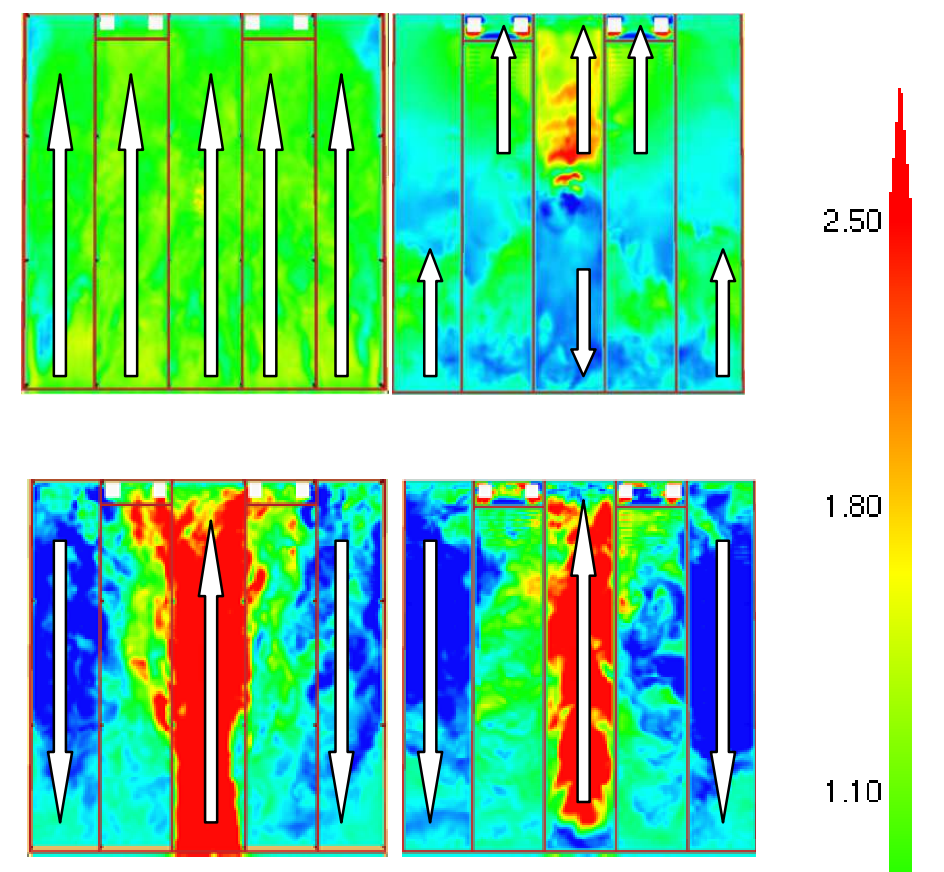

1.80

1.10
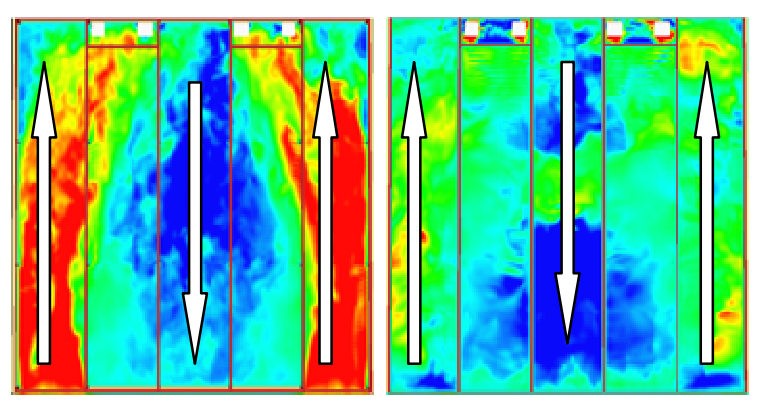

0.40

$-0.30$
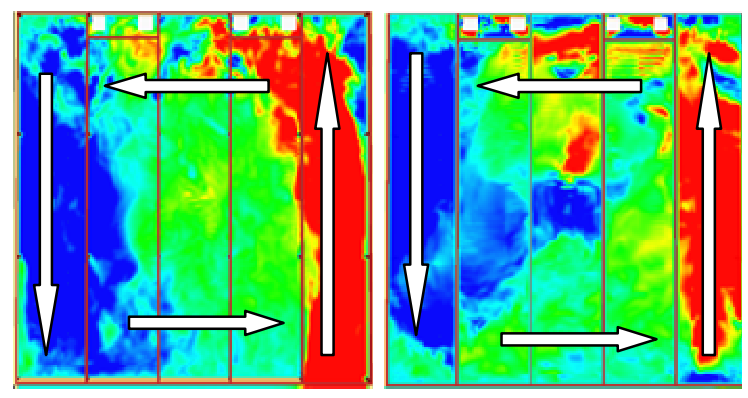

$-1.00$

Figure 8. Longitudinal velocity in horizontal planes at height $\mathrm{Z}=1.2 \mathrm{~m}$ (left) and $\mathrm{Z}=2.65 \mathrm{~m}$ (right). Fire HRR $=500 \mathrm{~kW}$, smoke extraction rate $=200000 \mathrm{~m} 3 / \mathrm{h}$. Top: OOOOO; 2nd row: XXOXX; 3rd row: OXXXO; bottom: XXXXO. Negative values indicate recirculation. Arrows indicate flow pattern. 

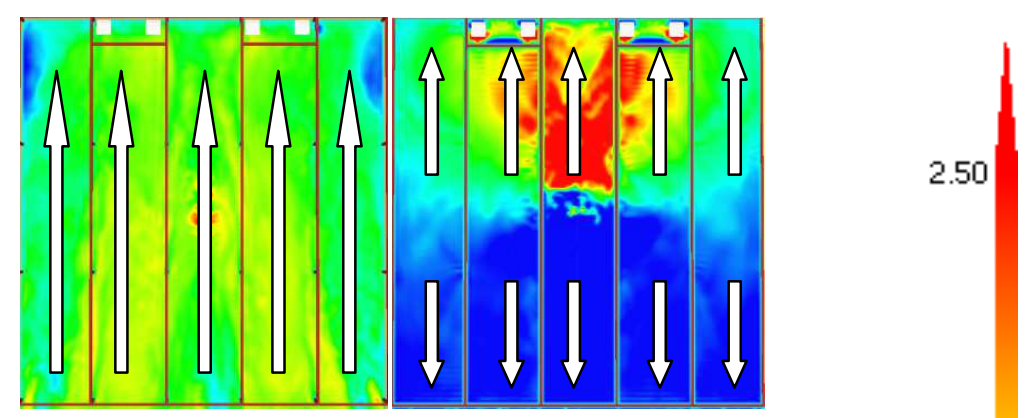

1.80
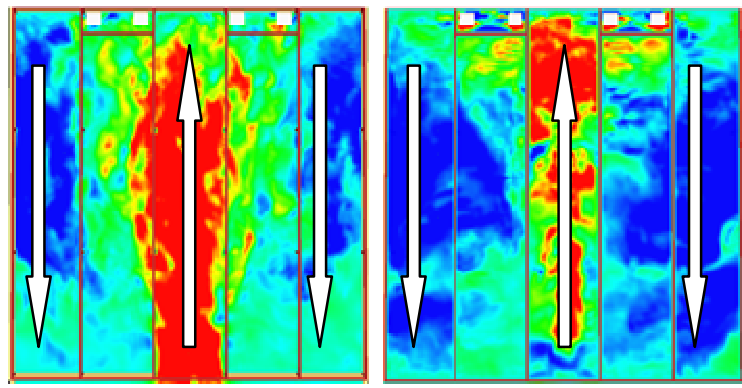

1.10
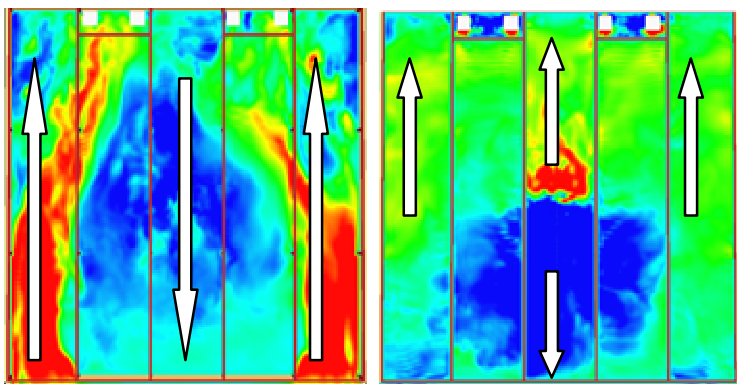

0.40

$-0.30$
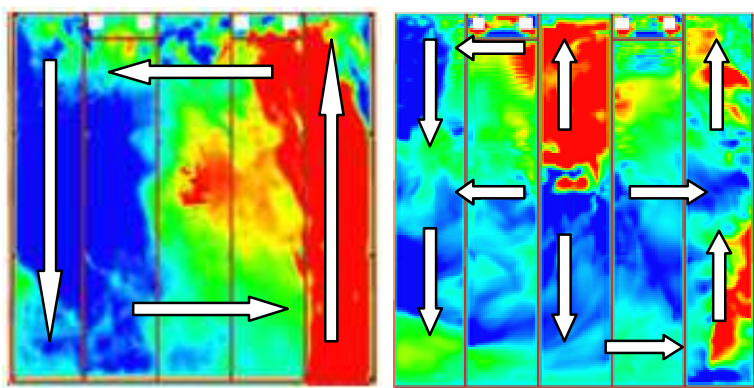

Figure 9. Longitudinal velocity in horizontal planes at height $\mathrm{Z}=1.2 \mathrm{~m}$ (left) and $\mathrm{Z}=2.65 \mathrm{~m}$ (right). Fire HRR $=4 \mathrm{MW}$, smoke extraction rate $=200000 \mathrm{~m} 3 / \mathrm{h}$. Top: OOOOO; 2nd row: XXOXX; 3rd row: OXXXO; bottom: XXXXO. Negative values indicate recirculation. Arrows indicate flow pattern. 
Figure 10 shows the resulting mean temperature profiles along the different thermocouple lines under the ceiling for $500 \mathrm{~kW}$ and $4 \mathrm{MW}$. Recall that mainly the profile shape is important, rather than absolute values. The impact of the flow pattern is clearly huge, as could be expected from Figures 8 and 9. For OOOOO, agreement between simulations and experiments is good, both for $500 \mathrm{~kW}$ and $4 \mathrm{MW}$, as discussed before (Figure 7). For XXOXX, it has already been mentioned that the spreading of the incoming air flow through $\mathrm{O}$ is probably under-estimated in FDS, leading to lower temperatures and a shift of the temperature peak towards the back side of the car park in the centerline profile. Yet, the order of magnitude in shift from OOOOO to XXOXX is well captured. For the $500 \mathrm{~kW}$ HRR, essentially no temperature rise is observed, nor in the experiments, nor in the simulations. The configurations OXXXO and XXXXO are more complex, as they involve recirculation patterns. If these are not well predicted, seemingly large deviations between experiments and temperature profiles from the simulations must become visible. Agreement between experiments and simulations is indeed less satisfactory. The upstream shift of the position of peak temperature due to the recirculation zone in the OXXXO set-up is well predicted, but the shift in position is too strong in the simulations and the temperatures relatively too high. This is again an indication of too low turbulence levels: there is less mixing in the flow, causing too strong recirculation and too low temperature fluctuations. The most complex case, XXXXO, is relatively poorly predicted for the $500 \mathrm{~kW} \mathrm{HRR}$, basically again due to too strong recirculation (lack of turbulent mixing). Interestingly, the agreement is better for the 4 MW HRR: as the fire source becomes stronger, the impact of the incoming air flow loses strength compared to the smoke's own dynamics and FDS provides simulation results in better agreement with the experimental data. 


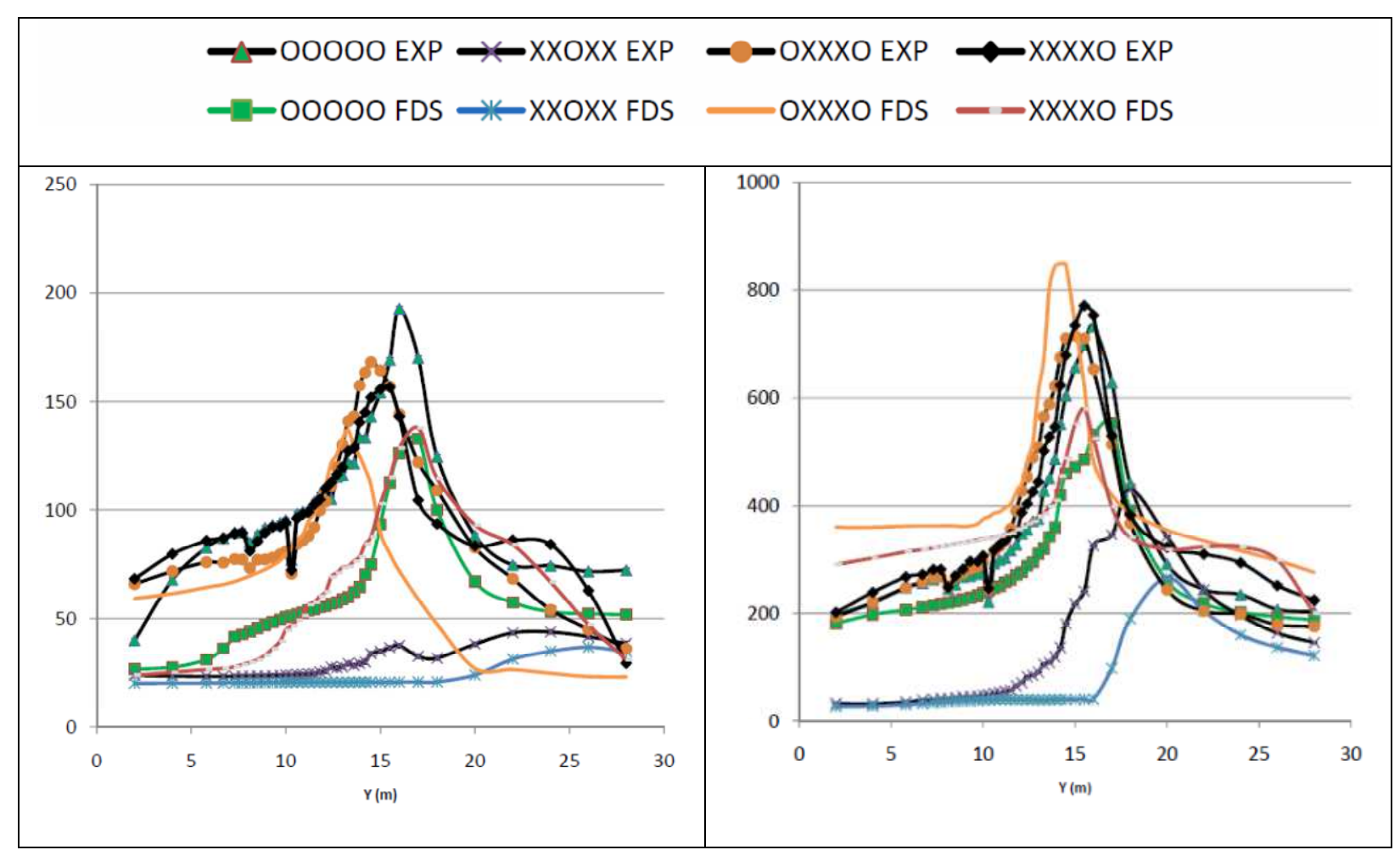

Figure 10. Centerline profiles of mean temperature $\left({ }^{\circ} \mathrm{C}\right)$ under the ceiling for $\mathrm{HRR}=500 \mathrm{~kW}$ (left) and 4 MW (right) for OOOOO, XXOXX, OXXXO and XXXXO. Smoke extraction rate = $200000 \mathrm{~m}^{3} / \mathrm{h}$

Activation of the jet fans hardly affects the results. This is probably due to the quite strongly downward angle at the jet fans' exit: the situation at the ceiling is hardly affected in the set-up at hand.

Thus far, the discussion focused on confirmation of the observations made in the full-scale experiments of [1]. It is re-assuring and comforting that trends are essentially well captured in the CFD simulations. As such, it can be concluded at this stage that CFD simulations are a reliable tool in the design stage, provided they are performed appropriately.

Now the discussion is extended to cases which have not been examined experimentally. More particularly, the effect of increased smoke extraction rate $\left(400000 \mathrm{~m}^{3} / \mathrm{h}\right)$ is examined for the 
different inlet opening configurations or, in other words, for the different resulting flow patterns. The intuitive expectation is that increasing the smoke extraction rate results in lower temperatures, less smoke back-layering and more back-ward flame tilting. Comparison of Figures 10 and 11, however, reveals that this is only true for the OOOOO and XXOXX configuration, where the oncoming air flow 'cannot miss' the fire source, i.e. the oncoming air flow is essentially unidirectional from inlet to extraction point and 'hits' the fire source automatically. In the OOOOO configuration, the extraction rate of $400000 \mathrm{~m}^{3} / \mathrm{h}$ is sufficient to prevent smoke back-layering up to the car park inlet for the $4 \mathrm{MW}$ fire HRR (the temperature becomes ambient temperature near the inlet). This is in line with the correlation of [11].

A more important observation is that, in all configurations, the basic flow pattern does not change when the smoke extraction rate increases (not shown). In particular, recirculation regions do not disappear or change in shape. As a consequence, in configurations OXXXO and XXXXO, where the fire source is inside a recirculation region behind the $\mathrm{XXX}(\mathrm{X})$ parts of the inlet opening, much of the incoming air bypasses the fire source to a certain extent and the smoke is trapped inside the recirculation region. Increasing the smoke extraction rate clearly does not help to extract the smoke more efficiently. Indeed, in Figure 11, even for the low fire HRR of 500 $\mathrm{kW}$, though the temperatures are lower due to more cooling by the increased air flow rate, the presence of smoke near the car park inlet $(\mathrm{Y}=0 \mathrm{~m})$ is practically the same as in Figure 10 for the OXXXO and XXXXO configuration.

$$
- \text { - } 00000 \text { FDS } \rightarrow \text { - } X X X X X F D S \longrightarrow \text { OXXXO FDS }--X X X X \text { FDS }
$$




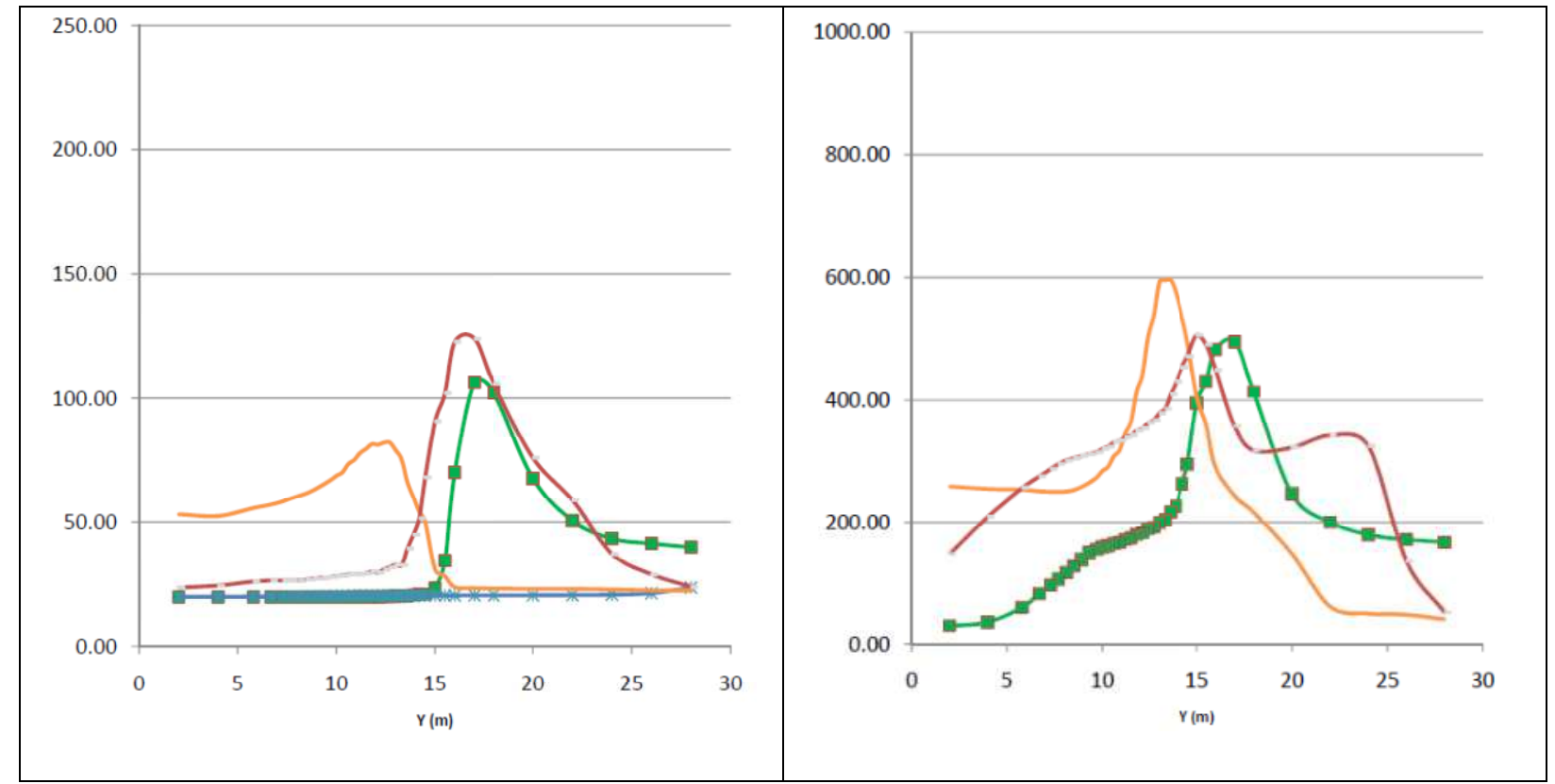

Figure 11. Centerline profiles of mean temperature $\left({ }^{\circ} \mathrm{C}\right)$ under the ceiling for $\mathrm{HRR}=500 \mathrm{~kW}$ (left) and 4 MW (right) for OOOOO, XXOXX, OXXXO and XXXXO. Smoke extraction rate = $400000 \mathrm{~m}^{3} / \mathrm{h}$

\section{d. Impact of Presence of Beams}

In this section the possible impact of the presence of longitudinal and transversal beams is examined. As in the previous sections, the configuration of [1] is examined first, i.e. a $17 \mathrm{~m}$ long transversal beam of $50 \mathrm{~cm}$ depth is positioned at position $\mathrm{Y}=10 \mathrm{~m}$. Figure 12 shows a snapshot of the temperature in the vertical symmetry plane for HRR equal to $4 \mathrm{MW}$ for OOOOO and XXOXX. In the OOOOO configuration, the blocking effect by the beam is clearly observed (but smoke back-layering up to the car park inlet is not prevented). In the XXOXX configuration, the effect of the beam is minor: also without beam the air velocity was high enough to prevent smoke back-layering. For OXXXO and XXXXO, there is a recirculation region and the effect of the beam is not very crucial.
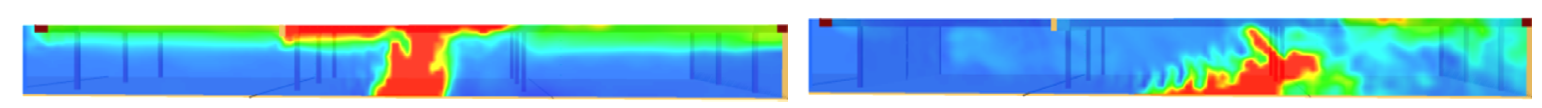
Figure 12. Temperature in vertical symmetry plane. Left: OOOOO; right: XXOXX. Fire HRR = $4 \mathrm{MW}$. Smoke extraction rate $=200000 \mathrm{~m}^{3} / \mathrm{h}$.

Figure 13 allows a quantitative discussion. For the $500 \mathrm{~kW}$ fire HRR, the effect of the beam is negligible in the XXOXX configuration: regardless of the presence of the beam, there is hardly any temperature rise due to the very strong oncoming air flow. In the OXXXO configuration, the beam is situated inside the recirculation region and, although a temperature jump is observed at the beam location, the effect of the beam is small, as already mentioned. In the OOOOO configuration, though, the beam effectively blocks the smoke and back-layering up to the car park inlet is avoided. The explanation is simple: the momentum of the smoke, flowing at the ceiling, is broken and the momentum of the oncoming air suffices to push the smoke, trying to flow beneath the beam, backward. For the $4 \mathrm{MW}$ fire HRR, this is not true: a clear temperature jump is observed at the beam location, but back-layering is visible up until the car park inlet, in line with Figure 12. Behind the beam, in the fire source area, temperatures are higher than when the beam is absent: the fresh air cannot reach this region and as such, there is less cooling effect. In the XXOXX configuration, the effect of the beam is negligible again, as could be expected.

The effect of the jet fans, implemented as described above, is small (not shown).
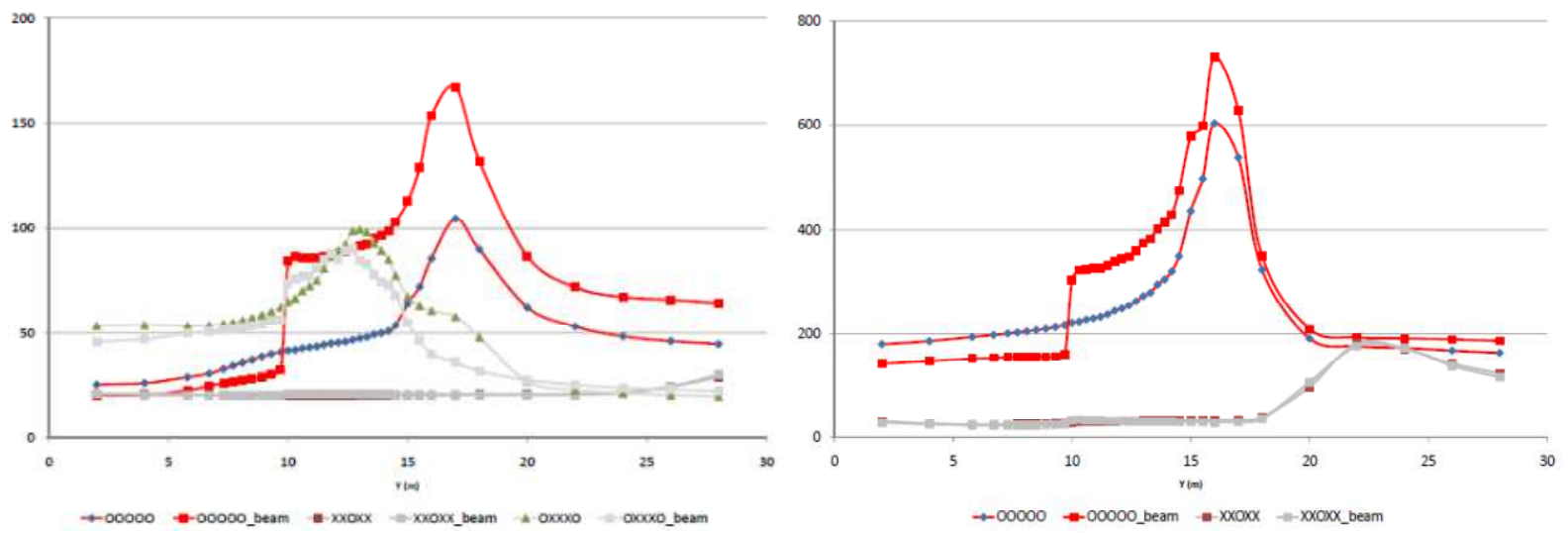
Figure 13. Profiles of mean temperature $\left({ }^{\circ} \mathrm{C}\right)$ along the centerline under the ceiling for $\mathrm{HRR}=$ $500 \mathrm{~kW}$ (left) and $4 \mathrm{MW}$ (right) for OOOOO, XXOXX and OXXXO, with and without transversal beam. Smoke extraction rate $=200000 \mathrm{~m}^{3} / \mathrm{h}$.

Clearly, the presence of beams is very important. Therefore, the CFD study has been extended beyond what has been measured in [1]. Obviously, care must be taken not to accept the results obtained (reported in Table 3) as perfect representations of reality. The results from the previous sections provide some confidence in the quality of the CFD results. Still, the numbers as obtained from the simulations must be regarded as indicative for reality, not as absolute values without any uncertainty.

Pressure losses are not considered: a fixed extraction rate is imposed, regardless of possible pressure losses due to flow obstruction. Figure 14 summarises the results in terms of backlayering distance and smoke extraction rate for a 4 MW HRR fire in a $30 \mathrm{~m}$ x $30 \mathrm{~m}$ x $2.4 \mathrm{~m}$ car park. The following observations can be made:

- For a flat ceiling, the extraction flow rate, corresponding to a back-layering distance $d$ of $15 \mathrm{~m}$, is around $300000 \mathrm{~m}^{3} / \mathrm{h}$, with an inlet air velocity of about $1.1 \mathrm{~m} / \mathrm{s}$.

- When $40 \mathrm{~cm}$ deep longitudinal beams are present (with distance of $11 \mathrm{~m}$ in between them here), the extraction flow rate for $d=15 \mathrm{~m}$ increases to $355000 \mathrm{~m}^{3} / \mathrm{h}$, i.e. an increase of almost $20 \%$ compared to a flat ceiling. This is due to the channeling effect by the beams: the momentum of the smoke from the fire source is directed more into the longitudinal direction, so that more momentum is required in the ventilation air flow.

- When a $40 \mathrm{~cm}$ deep transversal beam is present, the extraction flow rate for $d=15 \mathrm{~m}$ decreases to around $290000 \mathrm{~m}^{3} / \mathrm{h}$. In this case, the main effect is the breaking of the 
momentum of the smoke in the longitudinal direction. The oncoming air is forced under the beam and as such even gains momentum. Interestingly, the decrease in required extraction rate for a back-layering distance of $15 \mathrm{~m}$, compared to the flat ceiling configuration, is much smaller than the reduction in cross-section area for the air flow (height reduction from $2.4 \mathrm{~m}$ to $2 \mathrm{~m}$ ), implying that the required average velocity beneath the beam is higher than what is needed in a flat ceiling configuration. This implies that design calculations, based on the free height between floor and bottom side of beams, using velocities for flat ceilings, are not safe. As soon as the extraction rate exceeds $320000 \mathrm{~m}^{3} / \mathrm{h}$, the smoke is effectively blocked by the beam.

- When both transversal and longitudinal beams are present, the combined effect strongly depends on the beam depth. The global trend is a decrease in required extraction flow rate as the beam depth increases. For $20 \mathrm{~cm}$ deep beams, the extraction flow rate for $d=15 \mathrm{~m}$ is around $295000 \mathrm{~m}^{3} / \mathrm{h}$, which is comparable to what is obtained with the flat ceiling. For $40 \mathrm{~cm}$ deep beams, the extraction flow rate is around $270000 \mathrm{~m}^{3} / \mathrm{h}$. Interestingly, this is lower than for the configuration with only a transversal beam. The reason is that, with both transversal and longitudinal beams, the smoke momentum is broken in all directions. In the case of a transversal beam alone, the sideward momentum of the smoke is so strong that, hitting the side walls, smoke back-layering is more pronounced there and the required extraction flow rate to limit back-layering to a distance of $15 \mathrm{~m}$ is higher. This effect would not be visible if the side walls were further away.

Transform the extraction flow rates to average air velocities, determined as the average velocity from floor to either bottom side of beams or to ceiling height (when no transversal beam is present), reveals that all velocities are clearly higher than the value for the flat ceiling (Table 3). 
This implies that SHC design calculations, determining the required smoke extraction rate from average velocities below beams and assuming these velocities are the same as for a flat ceiling configuration, are not conservative.

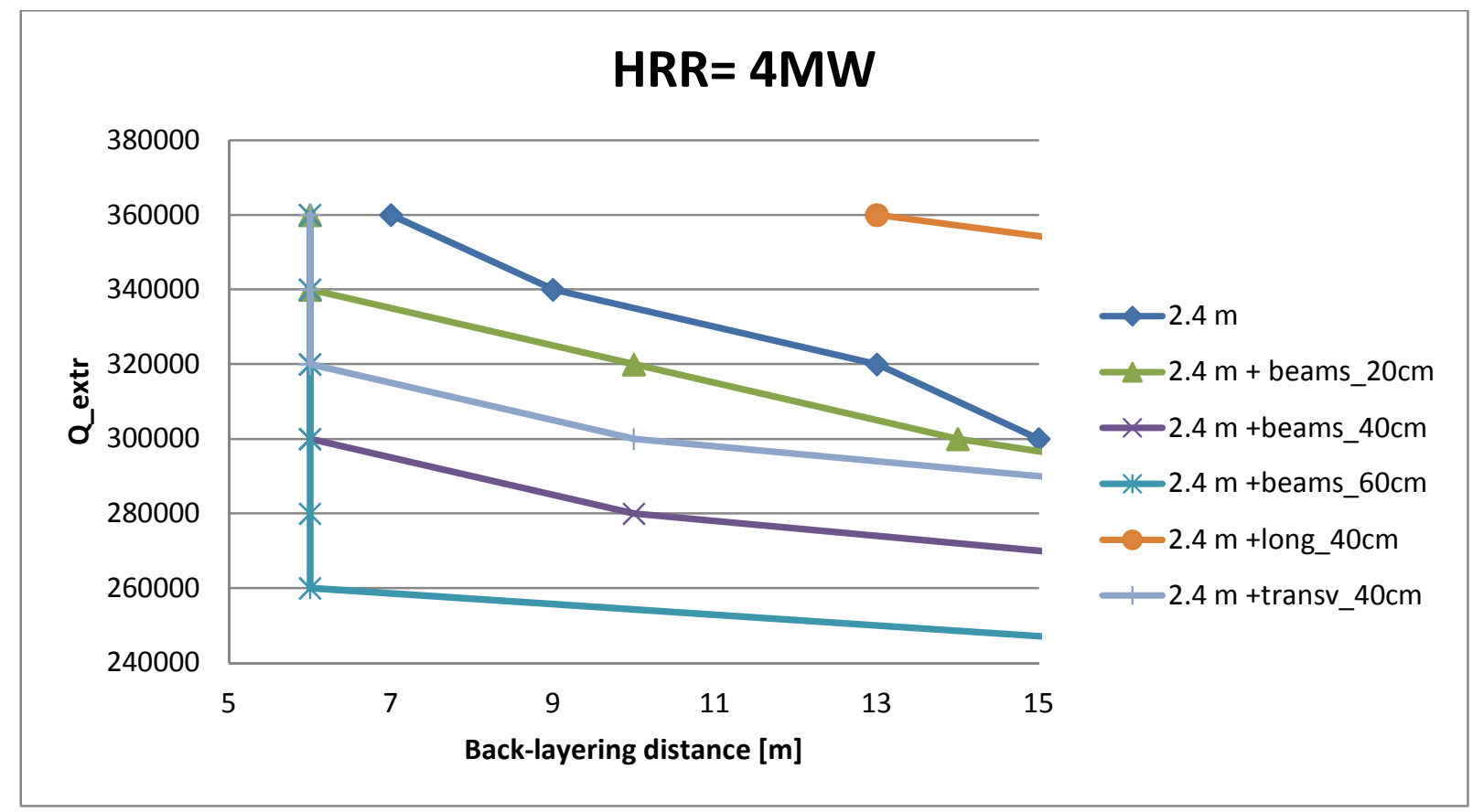

Figure 14. Variation of back-layering distance with smoke extraction rate for a 4 MW fire (30 \% radiation losses) in a $30 \mathrm{~m}$ x $30 \mathrm{~m}$ x $2.4 \mathrm{~m}$ car park, OOOOO configuration.

\begin{tabular}{|l|l|l|l|l|l|l|}
\hline Config. & Flat & L_40cm & T_40cm & LT_20cm & LT_40cm & LT_60cm \\
\hline $\mathbf{V}_{\text {air,av }}(\mathbf{m} / \mathbf{s})$ & 1.1 & 1.25 & 1.23 & 1.15 & 1.15 & 1.17 \\
\hline
\end{tabular}

Table 3. Required average air velocity (from floor level to bottom side of beams or to ceiling height) as obtained from the simulations to limit the smoke back-layering distance to $d=15 \mathrm{~m}$ for a 4 MW fire in a $30 \mathrm{~m} \times 30 \mathrm{~m} \times 2.4 \mathrm{~m}$ car park. L: longitudinal beams present; T: transversal beams present. 


\section{Conclusions}

CFD results have been presented for a large number of car park fire configurations. The following conclusions can be drawn:

- The trends, observed in full-scale experiments, are captured well, so that CFD simulations, when performed properly, are reliable and complementary to experiments in the sense that additional insight is gained from the CFD.

- As long as the flow is essentially unidirectional, increased fire HRR and decreased smoke extraction rates lead to more smoke back-layering, the effect of the smoke extraction rate being much stronger than the fire HRR.

- When recirculation regions appear and smoke gets trapped, increasing the smoke extraction rate is not a solution to remove the smoke.

- On the meshes applied, FDS has the tendency to under-predict turbulent mixing of the incoming air flow with the flows inside the car park, probably due to lack of turbulence at inlet openings. As a consequence, differences in flow patterns due to modifications in the car park inlet opening are too much pronounced in the simulations. Still, the simulated flow patterns agree well with experimental observations.

- When beams are present, the required smoke extraction rate decreases when there are transversal beams and increases when there are only longitudinal beams. In any case, the average velocity between floor and bottom side of beams is higher than for the flat ceiling configuration, so that design calculations based on a flat ceiling are not safe.

- The order of magnitude of required air velocity to limit smoke back-layering to a distance of $15 \mathrm{~m}$ for a $4 \mathrm{MW}$ fire, representative of a car fire, is $1.1 \mathrm{~m} / \mathrm{s}$. 


\section{Acknowledgements}

The results presented have been obtained through the SBO project 080010 , funded by IWT (Flanders, Belgium).

\section{References}

[1] X. Deckers, S. Haga, N. Tilley, B. Sette and B. Merci, "Smoke control in case of fire in a large car park: Full-Scale Experiments", Fire Safety Journal (submitted).

[2] W.K. Chow, "Use of a Time Constant for Designing a Smoke Control System in Car Parks", J. of Fire Sciences 13 (5), pp. 357-377 (1995).

[3] F. Colella G. Rein, R. Borchiellini and J.L. Torero, "A Novel Multiscale Methodology for Simulating Tunnel Ventilation Flows during Fires”, Fire Technology (2011), 47(1):221-253

[4]. B. Merci and M. Sjipp, "Smoke and heat control for fires in large car parks: Lessons learnt from research?”,Fire Safety Journal (submitted).

[5] F. Colella, G. Rein, R. Carvel, P. Reszka and J.L. Torero "Analysis of the ventilation systems in the Dartford tunnels using a multi-scale modelling approach", Tunnelling and Underground Space Technology 25, pp. 423-432 (2010).

[6] F. Colella, G. Rein, R. Borchiellini and V. Verda "Multiscale Modelling of the Transient Flows from Fire and Ventilation in Long Tunnels, Computer \& Fluids (2011), 51(1): 16-29.

[7] K. Kang, "A smoke model and its application for smoke management in an underground mass transit station " Fire Safety Journal 42 (3), pp. 218-231 (2007).

[8] S. Kumar, G. Cox, P.H. Thomas, “Air entrainment into balcony spill plumes”, Fire Safety Journal 45 (3), pp. 159-167 (2010).

[9] N. Tilley, P. Rauwoens and B. Merci, "Verification of the Accuracy of CFD Simulations in Small-Scale Tunnel and Atrium Fire Configurations", Fire Safety Journal 46, pp. 186 - 193 (2011).

[10] Fire Dynamics Simulator (Version 5), National Institute of Standards and Technology, USA (2010). http://www. fire.nist.gov/fds/

[11] S.B. Pope, Turbulent Flows, Cambridge University Press (2000).

[12] K. Van Maele and B. Merci, "Application of RANS and LES Field Simulations to Predict the Critical Ventilation Velocity in Longitudinally Ventilated Horizontal Tunnels", Fire Safety Journal 43 (8), pp. 598-609 (2008). 
[13] NBN S21-208-2: "Fire protection inside buildings - Design of smoke and heat exhaust ventilation systems (SHEVS) for indoor car parks”, Belgium (2011).

[14] B.J.M. v.d.Giesen, S.H.A. Penders, M.G.L.C. Loomans, P.G.S. Rutten and J.L.M. Hensen, "Modelling and simulation of a jet fan for controlled air flow in large enclosures", Environmental Modelling \& Software 26 (2011) 191-200.

[15] S. Brohez, C. Delvosalle and G. Marlair, "A two-thermocouples probe for radiation corrections of measured temperatures in compartment fires", Fire Safety Journal, 39 (5) (2004) $399-411$

[16] N. Tilley, X. Deckers and B. Merci, "CFD Study of Ventilation Velocity and Smoke BackLayering Distance in Car Parks", Fire Safety Journal (submitted). 